This document is confidential and is proprietary to the American Chemical Society and its authors. Do not copy or disclose without written permission. If you have received this item in error, notify the sender and delete all copies.

\title{
Helix Fraying and Lipid-Dependent Structure of a Short Amphipathic Membrane-Bound Peptide Revealed by Solid- State NMR
}

\begin{tabular}{|r|l|}
\hline Journal: & The Journal of Physical Chemistry \\
\hline Manuscript ID & jp-2018-02661u.R1 \\
\hline Manuscript Type: & Article \\
\hline Date Submitted by the Author: & n/a \\
\hline Complete List of Authors: & $\begin{array}{l}\text { Strandberg, Erik; Karlsruhe Institute of Technology, Institute of Biological } \\
\text { Interfaces (IBG-2) } \\
\text { Grau-Campistany, Ariadna; University of Barcelona, Faculty of Chemistry, } \\
\text { Department of Organic Chemistry } \\
\text { Wadhwani, Parvesh; Karlsruhe Institute of Technology, Institute for } \\
\text { Biological Interfaces, IBG-2 } \\
\text { Bürck, Jochen; Karlsruhe Institute of Technology (KIT), Institute of } \\
\text { Biological Interfaces (IBG-2) } \\
\text { Rabanal, Francesc; University of Barcelona, Organic Chemistry Section } \\
\text { Ulrich, Anne; KIT, Inst. Org. Chem. }\end{array}$ \\
\hline
\end{tabular}

\section{SCHOLARONE ${ }^{\mathrm{m}}$ \\ Manuscripts}




\title{
Helix Fraying and Lipid-Dependent Structure of a Short Amphipathic Membrane-Bound Peptide Revealed by Solid-State NMR
}

\author{
Erik Strandberg ${ }^{1}$, Ariadna Grau-Campistany ${ }^{2}$, Parvesh Wadhwani ${ }^{1}$, Jochen Bürck ${ }^{1}$, Francesc \\ Rabanal $^{2}$, and Anne S. Ulrich ${ }^{1,3, *}$ \\ ${ }^{1}$ Karlsruhe Institute of Technology (KIT), Institute of Biological Interfaces (IBG-2), POB \\ 3640, 76021 Karlsruhe, Germany; ${ }^{2}$ Secció de Química Orgànica, Departament de Química \\ Inorgànica i Orgànica, Facultat de Química, Universitat de Barcelona, Barcelona, Spain; \\ ${ }^{3}$ KIT, Institute of Organic Chemistry, Fritz-Haber-Weg 6, 76131 Karlsruhe, Germany \\ * Corresponding author \\ Email: anne.ulrich@,kit.edu \\ Phone: +49721608
}

\section{ORCIDS:}

Erik Strandberg: $\quad$ 0000-0002-2401-7478

Ariadna Grau-Campistany: 0000-0001-8236-9204

Parvesh Wadhwani: $\quad$ 0000-0002-7290-5154

Jochen Bürck: 0000-0002-2256-9498

Francesc Rabanal: $\quad$ 0000-0002-4913-155X

Anne S. Ulrich: $\quad$ 0000-0001-5571-9483 


\begin{abstract}
The amphipathic $\alpha$-helical peptide KIA14 [(KIAGKIA $\left.)_{2}-\mathrm{NH}_{2}\right]$ was studied in membranes using circular dichroism and solid-state NMR spectroscopy, to obtain global as well as local structural information. By analyzing ${ }^{2} \mathrm{H}-\mathrm{NMR}$ data from ten analogues of KIA14 that were selectively labelled with Ala- $\mathrm{d}_{3}$, those positions that are properly folded into a helix could be determined within the membrane-bound peptide. The N-terminus was found to be unravelled, while positions 4-14 formed an ideal helix all the way to the C-terminus. The helicity did not change when Gly residues were replaced by Ala- $\mathrm{d}_{3}$, but was reduced when Ile was replaced, indicating that large hydrophobic residues are required for membrane binding and helix formation. The reduced helicity was strongly correlated with a decrease in peptide-induced leakage from lipid vesicles. The orientation of the short KIA14 peptide was assessed in several lipid systems and compared with that of the longer KIA21 sequence [(KIAGKIA $)_{3}$ $\mathrm{NH}_{2}$ ]. In DOPC, both peptides are aligned flat on the membrane surface, whereas in DMPC/lyso-MPC both are inserted into the membrane in an upright orientation. These two types of lipid systems had been selected for their strongly negative and positive spontaneous curvature, respectively. We propose that in these cases the peptide orientation is largely determined by the lipid properties. On the other hand, in plain DMPC and DLPC, which have only a slight positive curvature, a marked difference in orientation is evident: the short KIA14 lies almost flat on the membrane surface, while the longer KIA21 is more tilted. We thus propose that out of the lipid systems tested here, DMPC (with hardly any curvature) is the least biased lipid system in which peptide orientation and re-alignment can be studied, allowing to compare and discriminate the intrinsic effects of the properties of the peptides as such.
\end{abstract}




\section{Introduction}

Membrane-associated peptides perform many important biological functions. Some prominent groups of membrane-active peptides include antimicrobial peptides (AMPs) that kill microorganisms by permeabilizing the cell membrane, ${ }^{1-3}$ cell-penetrating peptides that penetrate lipid bilayers and can carry cargo inside without killing the cells, ${ }^{4-5}$ and fusogenic peptides that induce cell fusion. ${ }^{6-8}$ Despite a plethora of biophysical studies that have been carried out on these peptides in model membranes, their diverse mechanisms of action are still not fully understood with respect to the respective roles of peptide properties and lipid properties.

AMPs are found in almost all types of organisms and constitute host defence systems against microorganisms. ${ }^{1,9}$ Over 2000 AMPs have currently been identified. ${ }^{10}$ Linear cationic amphipathic $\alpha$-helices are one of the most common types and have the widest antimicrobial activity spectrum; some typical examples include magainins from frogs ${ }^{11}$ and LL-37 from humans. ${ }^{12}$ We recently showed that the activity of these AMPs can be strongly dependent on the peptide length ${ }^{13}$. A battery of peptides of various lengths containing the repeated basic sequence KIAGKIA, called KIA peptides, was designed from a subset of the antimicrobial PGLa from the magainin family. A systematic comparison of their membranolytic activities and membrane-bound structures showed that the helix must be long enough to span the hydrophobic region of the membrane to form pores, which are proposed to be responsible for function. ${ }^{13}$

As a first approximation of peptide length, we assumed that the peptides form an ideal $\alpha$-helix in which the helical rise is $1.5 \AA$ per residue. While this is a reasonable assumption for the central region of the helix, it may not be true closer to the termini. Circular dichroism spectroscopy (CD) was used to estimate the secondary structure elements of the KIA peptides, and an $\alpha$-helix content of $69-83 \%$ was found for this series. For example, the shortest peptide (KIA14, 14 amino acids) had a helicity of $74 \%$, which corresponds to 10 amino acids, while and the longer peptide (KIA21, also known as MSI-103, 21 amino acids) was 83\% helical, corresponding to 17 amino acids. ${ }^{14}$ These values suggest that approximately four residues in each peptide are not in a helical configuration, but it is not clear which residues are nonhelical, since $\mathrm{CD}$ does not provide local information. Helices are proposed to be frayed at the ends where the hydrogen bond pattern is not fulfilled. Because hydrogen bonds between the backbone atoms from position $n$ to $n+4$ exist in an $\alpha$-helix, the four residues closest to each 
terminus cannot participate fully in the hydrogen bond pattern. It is therefore likely that the central region of the peptide is helical, while the ends may be frayed.

A possible approach for experimentally detecting frayed membrane-bound peptides is to place a series of selective isotope-labels in the peptide and perform solid-state NMR in a membrane environment. From the measured NMR parameters, it is possible to find out whether and which of the labelled positions form an $\alpha$-helix. When the data are plotted as a helical wave, those points that deviate from the curve can indicate fraying. ${ }^{15-16}{ }^{2} \mathrm{H}-\mathrm{NMR}$ on Ala- $\mathrm{d}_{3}$ labeled peptides is especially useful on peptides containing several Ala in the sequence, where the labeling does not change the peptide, ${ }^{17-19}$ but can also be used as an Ala scan to determine the effect of replacing other residues. ${ }^{20}$

We have previously studied MSI-103 [(KIAGKIA $\left.)_{3}-\mathrm{NH}_{2}\right],{ }^{21-22}$ which will be called KIA21 herein to indicate similarity to KIA14, and determined its orientation in numerous lipid systems using ${ }^{2} \mathrm{H}-\mathrm{NMR},{ }^{23-24}$ The helix was found to assume different alignments depending on the spontaneous curvature of the lipid used. Namely, the peptide was aligned flat on the membrane surface in lipid bilayers with a negative spontaneous curvature (like POPC), but it flipped by about $30^{\circ}$ to become obliquely inserted in membranes with a small positive spontaneous curvature (like DMPC). ${ }^{24-25}$ For KIA21, only the central region of the peptide between positions 7 and 17 had been labelled, so no fraying effects were addressed. ${ }^{23-24}$ Here, we present a similar study of the shorter KIA14 [(KIAGKIA $)_{2}-\mathrm{NH}_{2}$ ], which was labelled with Ala- $\mathrm{d}_{3}$ one-by-one at every single position, except for the charged Lys residues, covering the entire length of the peptide from position 2 all the way to the C-terminus at position 14 . By measuring the corresponding quadrupolar splittings with ${ }^{2} \mathrm{H}-\mathrm{NMR}$ and fitting all these values to a helical curve, we could thus obtain the detailed orientation and dynamics of the short KIA14 helix in the membrane. These results can now be compared with the behaviour of KIA21 and other previously reported peptides. ${ }^{17-19,23,26-31}$ Furthermore, by assessing the fit of the individual data points to that of the overall helical wave curve, we can find out whether residues close to the termini deviate from the ideal helix curve. This kind of analysis reveals the stretch in which the KIA14 peptide forms an ideal helix, and it showed how close to the termini this short helix exhibits frayed ends. Furthermore, the NMR data can also be compared with $\mathrm{CD}$ data to assess the global and local helicity, and with functional data from vesicle leakage experiments to correlate helicity with membrane activity. 
Both KIA14 and KIA21 form $\alpha$-helices and have a similar distribution of amino acids around the helix, with a narrow polar sector (Figure 1). While KIA21 shows high activity in terms of antimicrobial effects, leakage of lipid vesicles, and well as haemolysis, KIA14 is inactive, most likely because it is too short to span the membrane in the form of pores that cause leakage and can kill bacteria and erythrocytes. ${ }^{13}$ In our previous studies, we had monitored the membrane alignment of KIA21 and KIA14 as a function of peptide concentration, in an attempt to correlate membrane behaviour and biological activity. ${ }^{14,24}$ Here, we have carefully analysed KIA14 in four different types of model membranes so that it can be compared with KIA21, because lipid composition is generally known to affect the re-alignment of peptides, but the roles and relative contributions of hydrophobic thickness and spontaneous curvature are not yet fully understood.
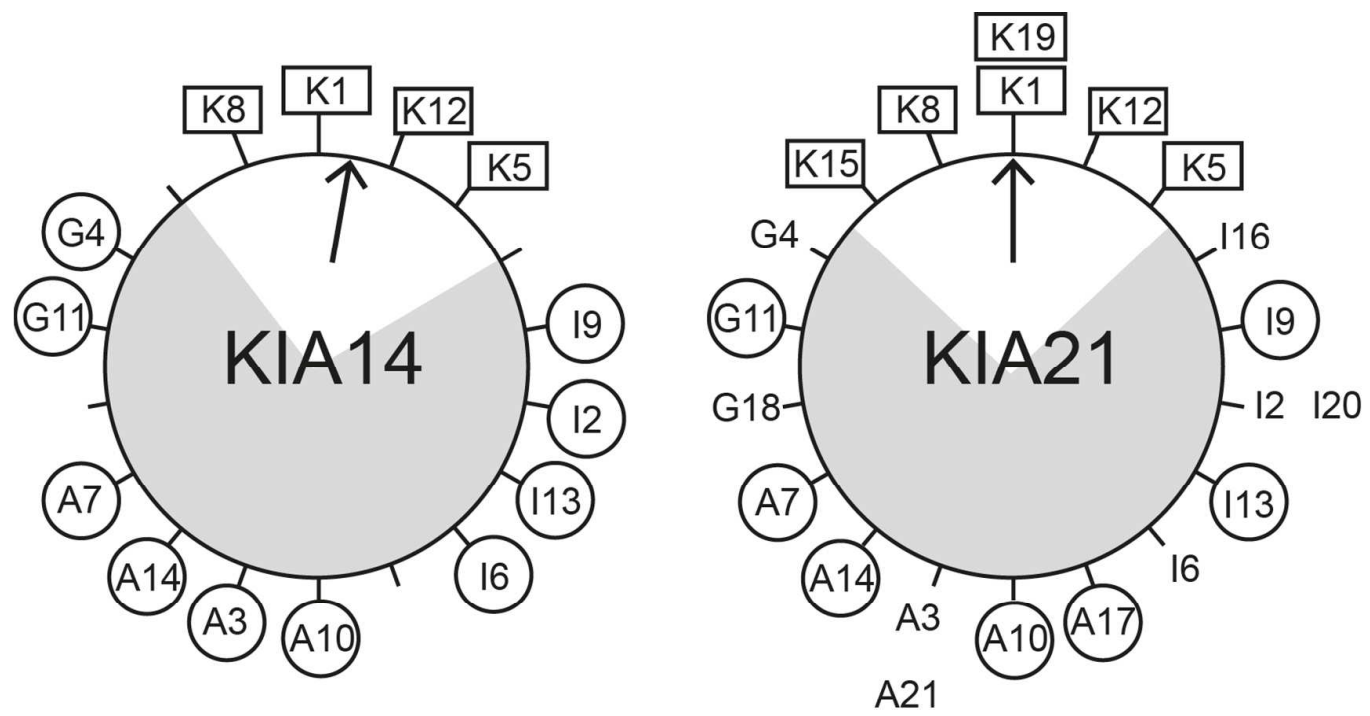

Figure 1. Helical wheel projection of KIA14 and KIA21. The hydrophobic sector is shaded. Charged Lys residues are indicated with boxes, and ${ }^{2} \mathrm{H}$-labelled positions are marked with circles. The centre of the polar sector is marked with an arrow. 


\section{Materials and Methods}

\section{Materials}

Peptide synthesis reagents and Fmoc-protected amino acids were purchased from Merck Biosciences (Darmstadt, Germany) and Iris Biotech (Marktredwitz, Germany). ${ }^{2} \mathrm{H}$-labelled 2,2,2- ${ }^{2} \mathrm{H}_{3}-L$-Ala $\left(\mathrm{Ala}_{3} \mathrm{~d}_{3}\right.$ ) was purchased from Cambridge Isotope Laboratories (Andover, MA, USA), and its N-terminus was Fmoc-protected. ${ }^{32}$ Solvents were purchased from Merck (Darmstadt, Germany). The lipids 1,2-dimyristoyl-sn-glycero-3-phosphatidylcholine (DMPC), 1-myristoyl-2-hydroxy-sn-glycero-3-phosphatidylcholine (lyso-MPC), 1,2dimyristoleoyl-sn-glycero-3-phosphatidylcholine (DMoPC), 1,2-dimyristoleoyl-sn-glycero-3phosphatidylglycerol (DMoPG) 1,2-dioleoyl-sn-glycero-3-phosphatidylcholine (DOPC), and 1,2-dilauroyl-sn-glycero-3-phosphatidylcholine (DLPC) were obtained from Avanti Polar Lipids (Alabaster, AL, USA).

Table 1. Synthesized peptides used in the ${ }^{2} \mathrm{H}-\mathrm{NMR}$ analysis. The highlighted Ala- $\mathrm{d}_{3}$ was labeled with deuterium at the side chain methyl-group.

\begin{tabular}{|c|c|c|c|c|}
\hline Peptide & $\begin{array}{l}\text { Labeled } \\
\text { position }\end{array}$ & Sequence & $\begin{array}{l}\text { Theoretical } \\
M_{w}{ }^{a}\end{array}$ & $\begin{array}{l}M_{w} \text { from } \\
\text { MS }^{\text {b }}\end{array}$ \\
\hline KIA14 & None & KIAGKIAKIAGKIA-NH $_{2}$ & 1380.87 & 1381.97 \\
\hline KIA14-I2A & Ile-2 & K-Ala-d ${ }_{3}$-AGKIAKIAGKIA-NH ${ }_{2}$ & 1341.78 & 1342.92 \\
\hline KIA14-A3 & Ala-3 & KI-Ala-d $_{3}$-GKIAKIAGKIA-NH ${ }_{2}$ & 1383.87 & 1384.97 \\
\hline KIA14-G4A & Gly-4 & KIA-Ala-d $_{3}$-KIAKIAGKIA-NH ${ }_{2}$ & 1397.89 & 1398.99 \\
\hline KIA14-I6A & Ile-6 & KIAGK-Ala-d $_{3}$-AKIAGKIA-NH ${ }_{2}$ & 1341.78 & 1342.92 \\
\hline KIA14-A7 & Ala-7 & KIAGKI-Ala-d $_{3}$-KIAGKIA-NH ${ }_{2}$ & 1383.87 & 1384.96 \\
\hline KIA14-I9A & Ile-9 & KIAGKIAK-Ala-d $_{3}$-AGKIA-NH ${ }_{2}$ & 1341.78 & 1342.92 \\
\hline KIA14-A10 & Ala-10 & KIAGKIAKI-Ala-d $_{3}$-GKIA-NH ${ }_{2}$ & 1383.87 & 1384.96 \\
\hline KIA14-G11A & Gly-11 & KIAGKIAKIA-Ala-d $_{3}$-KIA-NH ${ }_{2}$ & 1397.89 & 1398.95 \\
\hline KIA14-I13A & Ile-13 & KIAGKIAKIAGK-Ala-d $_{3}-\mathrm{A}-\mathrm{NH}_{2}$ & 1341.78 & 1342.91 \\
\hline KIA14-A14 & Ala-14 & KIAGKIAKIAGKI-Ala-d $_{3}-\mathrm{NH}_{2}$ & 1383.87 & 1384.96 \\
\hline
\end{tabular}

${ }^{\mathrm{a}}$ Theoretical molecular weight in $\mathrm{g} / \mathrm{mol}$

${ }^{\mathrm{b}}$ MALDI-TOF m/z, $[\mathrm{M}+\mathrm{H}]^{+}$

\section{Peptide synthesis}

Peptides were synthesized on a fully automated parallel peptide synthesizer (Syro II, MultiSynTech GmbH, Witten, Germany) using standard solid phase Fmoc protocols, as previously reported. ${ }^{33}$ In each peptide analogue, a single residue was replaced with Ala-d $\mathrm{d}_{3}$. A list of the peptides and the Ala- $\mathrm{d}_{3}$ positions in each instance is provided in Table 1 . The crude 
material was purified by high-performance liquid chromatography (HPLC) on a Vydac C18 column using an acetonitrile/water gradient supplemented with $5 \mathrm{mM} \mathrm{HCl}$. The product identities were confirmed by observing a single peak on an analytical liquid chromatography system (Agilent 1100 series, Santa Clara, CA, USA) connected to a $\mu$ TOF (time-of-flight) mass spectrometer (Bruker Daltonics, Bremen, Germany), and they were shown to be at least $95 \%$ pure.

\section{Vesicle leakage assay}

Samples for fluorescence leakage experiments were prepared by entrapping the fluorophore ANTS and the quencher DPX within large unilamellar vesicles, as previously described. ${ }^{34-36}$ ANTS $(12.5 \mathrm{mM})$ and DPX $(45 \mathrm{mM})$ were mixed together in $50 \mathrm{mM} \mathrm{NaCl}$ and $10 \mathrm{mM}$ HEPES ( $\mathrm{pH} 7.5$ ) to prepare the buffer solution. Liposomes were prepared by co-dissolving DMoPC/DMoPG $(1 / 1 \mathrm{~mol} / \mathrm{mol})$ lipids in $\mathrm{CHCl}_{3} / \mathrm{MeOH}(1 / 1 \mathrm{v} / \mathrm{v})$, together with $0.1 \mathrm{~mol} \%$ Rhodamine-PE, by which the lipid loss during vesicle preparation and purification could be quantified. The lipid mixture was dried under nitrogen flow for 30-60 min, followed by vacuum overnight. Buffer solution was added to the falcon tube, and the lipid film was resuspended by vigorous vortexing, followed by 10 freeze(liquid $\mathrm{N}_{2}$ )-thaw $\left(37^{\circ} \mathrm{C}\right)$-vortex cycles. ${ }^{37}$ Large unilamellar vesicles (LUVs) were obtained by 41 -fold extrusion (Avanti Mini Extruder; Avanti Polar Lipids, Alabaster, AL) of the liposomes through a nuclepore polycarbonate membrane (pore size 100 nm, Whatman - GE Healthcare Europe, Freiburg, Germany) at room temperature. Unencapsulated ANTS and DPX were separated from the entrapped material by gel filtration, using spin columns filled with Sephacryl 100-HR (SigmaAldrich, Taufkirchen, Germany) and initially equilibrated with an elution buffer (150 mM $\mathrm{NaCl}, 10 \mathrm{mM}$ HEPES, $\mathrm{pH}$ 7.5) that balances the internal vesicle osmolarity. This purification was done before every measurement. Leakage of encapsulated ANTS was monitored by fluorescence dequenching of ANTS. ${ }^{38}$ Fluorescence measurements were performed in a thermostated cuvette with constant stirring at $30^{\circ} \mathrm{C}$ in the same buffer as for gel filtration. A FluoroMax2 spectrofluorimeter (HORIBA Jobin Yvon, Unterhaching, Germany) was used, setting the ANTS emission to $510 \mathrm{~nm}$ (5 nm slit) and its excitation to $355 \mathrm{~nm}$ ( $5 \mathrm{~nm}$ slit). The exact volume of vesicle solution needed for a final lipid concentration of $100 \mu \mathrm{M}$ was calculated, based on the Rhodamine (Rhod-PE) maximum fluorescence intensity of the prepared vesicles in comparison to the initial vesicles (before extrusion and purification). The peptides were solubilized in water at a concentration of $150 \mu \mathrm{M}$ (stock solution). For the leakage experiment, peptides were added to the cuvette containing the vesicles at the $\mathrm{P} / \mathrm{L}$ ratio 
to be tested, and fluorescence was monitored for $10 \mathrm{~min}$. After $10 \mathrm{~min}, 0.25 \mathrm{vol} \%$ Triton X100 was added to obtain the fluorescence value corresponding to $100 \%$ leakage. The level of $0 \%$ leakage corresponded to the fluorescence of the vesicles after $10 \mathrm{~min}$ in a reference sample without peptide.

\section{Circular dichroism spectropolarimetry (CD)}

CD samples were prepared by co-solubilizing DMPC and DMPG $(3: 1 \mathrm{~mol} / \mathrm{mol})$ in chloroform/methanol $(3: 1 \mathrm{v} / \mathrm{v})$. After drying, the lipid film was dispersed in phosphate buffer (10 mM, pH 7) and homogenized by 10 freeze-thaw cycles with vigorous vortexing after each cycle. Small unilamellar vesicles (SUVs) for CD samples were generated by sonicating for 16 min in an ultrasonic bath (UTR 200, Hielscher, Germany) at $35^{\circ} \mathrm{C}$ (above the phase transition of the lipids). CD spectra were recorded on a J-815 spectropolarimeter (JASCO, GroßUmstadt, Germany) between 260 and $185 \mathrm{~nm}$ at $0.1 \mathrm{~nm}$ intervals using $1 \mathrm{~mm}$ quartz glass cells (Suprasil, Hellma Analytics, Müllheim Germany) as previously reported ${ }^{39}$. The peptides were measured at $25^{\circ} \mathrm{C}$ in $10 \mathrm{mM}$ sodium phosphate buffer $\left(\mathrm{pH} \mathrm{7.0)}\right.$ ) and at $30^{\circ} \mathrm{C}$ in lipid vesicles composed of DMPC/DMPG (3:1). The average baseline of the pure solvent was subtracted. The typical peptide concentration of the final samples was $0.1 \mathrm{mg} / \mathrm{mL}$, and a peptide-to-lipid molar ratio $(\mathrm{P} / \mathrm{L})$ of 1:50 was used.

Secondary structure estimation from CD spectra was performed as previously described, ${ }^{20}$ using tools provided by the DICHROWEB online server. ${ }^{40-47}$

\section{Solid-state NMR}

Macroscopically oriented NMR samples were prepared using 0.5-0.8 $\mathrm{mg}$ of peptide and appropriate amounts of lipids to obtain samples with $\mathrm{P} / \mathrm{L}=1: 20$ or $\mathrm{P} / \mathrm{L}=1: 50$. The peptides and lipids were co-dissolved in $400 \mu \mathrm{L}$ of chloroform/methanol $(1: 1 \mathrm{v} / \mathrm{v})$ and spread onto 23 thin glass plates of the dimensions $9 \mathrm{~mm} \times 7.5 \mathrm{~mm} \times 0.08 \mathrm{~mm}$ (Marienfeld Laboratory Glassware, Lauda-Königshofen, Germany). The plates were air-dried for $1 \mathrm{~h}$ and then vacuum-dried overnight. They were stacked and placed into a hydration chamber with $96 \%$ relative humidity at $48^{\circ} \mathrm{C}$ for $18-24 \mathrm{~h}$ before being wrapped in parafilm and plastic foil for the NMR measurements.

All NMR measurements were carried out on a Bruker Avance 500 or $600 \mathrm{MHz}$ spectrometer (Bruker Biospin, Karlsruhe, Germany) at $308 \mathrm{~K} .{ }^{31} \mathrm{P}-\mathrm{NMR}$ was used to evaluate the lipid 
orientation quality in the samples using a Hahn echo sequence with phase cycling ${ }^{48}$ and ${ }^{1} \mathrm{H}$ decoupling. $200 \mathrm{~Hz}$ line broadening was applied to the spectra. ${ }^{2} \mathrm{H}-\mathrm{NMR}$ experiments were performed using a quadrupole echo sequence ${ }^{49}$ with a $90^{\circ}$ pulse of $4.5 \mu \mathrm{s}$, an echo delay of 70 $\mu \mathrm{s}$, a $100-\mathrm{ms}$ relaxation delay time, a $500-\mathrm{kHz}$ spectral width, and 2048 data points. A total of 100.000 to 1.000 .000 scans were collected. The oriented samples were placed in a flat coil probe such that the lipid bilayer normal was aligned parallel to the magnetic field. 200-1000 $\mathrm{Hz}$ line broadening was applied to the spectra to improve signal to noise, adapted to the sharpness of peaks to avoid a loss of resolution.

\section{NMR data analysis}

The orientation of a helical peptide in a membrane can be defined by two angles, the tilt angle $\tau$, defined as the angle between the long axis of the helix and the membrane normal, and the azimuthal rotation angle $\rho$, which defines the rotation of the peptide around its long axis. Using ${ }^{2} \mathrm{H}-\mathrm{NMR}$ data from the Ala- $\mathrm{d}_{3}$-labelled positions, the helix orientation was calculated from RMSD fits and quadrupolar wave plots as previously described. ${ }^{17,19,27,50}$

To calculate orientational constraints from the NMR data, a quadrupole coupling constant $\left(e^{2} q Q / h\right)$ of $167 \mathrm{kHz}$ for an aliphatic C-D bond was used, giving a maximum quadrupolar splitting of $84 \mathrm{kHz}$ for the $\mathrm{CD}_{3}$ groups of the Ala-d $\mathrm{d}_{3}$ labels. ${ }^{51}$ Thus, the quadrupolar splitting $\left(\Delta v_{\mathrm{q}}\right)$ is given by

$\Delta v_{\mathrm{q}}=84 \mathrm{kHz} \times 1 / 2\left\langle 3 \cos ^{2} \theta-1\right\rangle$

where \langle\rangle represent the time average, and $\theta$ represents the angle between the $\mathrm{C}-\mathrm{CD}_{3}$ bond and the external magnetic field $\mathrm{B}_{0}$.

The KIA14 peptide was modelled as an ideal $\alpha$-helix, and alignment of this helix was fit to the orientational constraints. In the molecular frame, the tilt angle $\tau$ defines the angle between the helix axis (defined from the $\mathrm{N}$ - to the $\mathrm{C}$-terminus) and the bilayer normal. The azimuthal angle $\rho$ is defined as a right-handed rotation around the helix axis, where $\rho=0^{\circ}$ indicates (by our definition) that a radial vector from the helix axis to the $\mathrm{C}_{\alpha}$ atom at position 12 is oriented parallel to the membrane surface. ${ }^{50,52}$ Orientation of the $\mathrm{C}_{\alpha}-\mathrm{C}_{\beta}$ bond in the molecular frame is defined by the angle $\beta$, the angle between the bond vector and the helix axis; the angle $\alpha$, which is defined by the vector radiating from the helix axis through the $\mathrm{C}_{\alpha}$ atom; and the 
projection of the $\mathrm{C}_{\alpha}-\mathrm{C}_{\beta}$ bond vector onto a plane perpendicular to the helix. In the same plane, the rotational angle between two consecutive amino acids along the helix is called $\omega$. We use for an $\alpha$-helix angular values of $\beta=121.1^{\circ}, \alpha=53.2^{\circ}$, and $\omega=100^{\circ}$, as determined from an $\alpha$ helical polyalanine model constructed in SYBYL (Tripos, St. Louis, MO, USA) based on the torsion angles $\varphi=-58^{\circ}$ and $\psi=-47^{\circ} .52$

Peptide dynamics are described as Gaussian distributions of $\tau$ and $\rho$ angles, with widths given by the standard deviations $\sigma_{\tau}$ and $\sigma_{\rho}$, respectively. Larger widths correspond to a more dynamic situation in which the helix undergoes whole-body fluctuations with larger amplitude. These fluctuations are assumed to be fast on the NMR time scale so that the measured splittings represent time averages over these distributions. ${ }^{27,53}$ Using a grid search to find the best-fit peptide structure, the helix is systematically rotated, and the theoretical quadrupole splittings are calculated for different combinations of $\tau, \rho, \sigma_{\tau}$ and $\sigma_{\rho}$. All parameters are changed in $1^{\circ}$ steps; $\tau$ and $\rho$ are examined from 0 to $180^{\circ}$ (due to symmetry), and $\sigma_{\tau}$ and $\sigma_{\rho}$ are investigated from 0 to $50^{\circ}$. These ranges have been established as being large enough to include the solution with the lowest root-mean-square deviation (RMSD) between calculated and experimental data. This best-fit combination of parameters is identified as providing the most likely orientation and dynamics of the peptide in the membrane.

By evaluating the deviation between the best-fit curve and individual data points, it is possible to determine whether a specific labelled residue is part of the helical region of the peptide and whether specific Ala mutations influence helicity. 


\section{Results}

\section{Peptide synthesis}

KIA14 and ten analogues in which Ala- $\mathrm{d}_{3}$ was inserted at various positions within the sequence (replacing all residues except for the four charged Lys residues) were successfully synthesized and purified. The peptides are listed in Table $\mathbf{1 .}$

\section{Vesicle leakage assay}

In previous studies of KIA peptides of different length, no antimicrobial nor hemolytic effect was found for the short KIA14 peptide. Neither did we observe any KIA14-induced vesicle leakage in lipid systems with a hydrophobic membrane thickness that was greater than the length of this short helix (estimated to be $21 \AA$, from the known length of $1.5 \AA$ per residue of an ideal $\alpha$-helix). Only in DMoPC/DMoPG, with a hydrophobic thickness of $19 \AA$, did KIA14 induce leakage. ${ }^{13,36}$ To investigate whether the Ala- $\mathrm{d}_{3}$ mutations had any influence on the activity of the peptide, leakage of KIA14 and its Gly $\rightarrow$ Ala- $\mathrm{d}_{3}$ and Ile $\rightarrow$ Ala- $\mathrm{d}_{3}$ mutants was monitored at $\mathrm{P} / \mathrm{L}=1: 100$ and 1:200. As seen in Table 2, the Gly $\rightarrow$ Ala- $\mathrm{d}_{3}$ mutants exhibited higher activity, whereas the Ile $\rightarrow$ Ala- $\mathrm{d}_{3}$ mutants showed much less leakage than the parent peptide. At P/L=1:100, KIA14, KIA14-G4A and KIA14-G11A gave close to $100 \%$ leakage, while the Ile $\rightarrow$ Ala- $\mathrm{d}_{3}$ mutants produced only $13-21 \%$ leakage.

Table 2. Leakage of DMoPC/DMoPG (1:1) vesicles induced by KIA14 and its Ala-d $\mathrm{d}_{3}$ mutants. The average and standard deviation calculated from at least three measurements for each peptide are shown.

\begin{tabular}{|l|r|r|}
\hline Peptide & $\begin{array}{l}\text { Leakage }(\%) \\
\mathrm{P} / \mathrm{L}=1: 200\end{array}$ & $\begin{array}{l}\text { Leakage }(\%) \\
\mathrm{P} / \mathrm{L}=1: 100\end{array}$ \\
\hline KIA14 & $65 \pm 5$ & $92 \pm 2$ \\
\hline KIA14-I2A & $15 \pm 3$ & $21 \pm 1$ \\
\hline KIA14-G4A & $78 \pm 3$ & 100 \\
\hline KIA14-I6A & $12 \pm 3$ & $16 \pm 1$ \\
\hline KIA14-I9A & $13 \pm 1$ & $18 \pm 2$ \\
\hline KIA14-G11A & $95 \pm 3$ & 100 \\
\hline KIA14-I13A & $9 \pm 2$ & $13 \pm 2$ \\
\hline
\end{tabular}

\section{Circular dichroism}

CD provides information about the secondary structure of peptides. The CD spectra of KIA14 
and the mutants in which Gly or Ile had been replaced by Ala- $\mathrm{d}_{3}$, were measured in phosphate buffer, and all peptides showed random coil spectra (Figure 2A). Measurements were also performed in DMPC/DMPG (3:1) vesicles, and all peptides gave CD spectral shapes typical of an $\alpha$-helical structure (Figure 2B). When the spectra were deconvoluted to determine the fraction of secondary structure elements as previously described, ${ }^{20}$ a highly variable amount of $\alpha$-helical content was observed (Table 3). The original KIA14 peptide and the Gly $\rightarrow$ Ala mutants are approximately $75 \%$ helical. However, the Ile $\rightarrow$ Ala mutants are found to be only $40-52 \%$ helical, which indicates that the large hydrophobic Ile residues are required to stabilize the helical fold in a membrane environment. For the 14-residue sequence (with 13 peptide bonds) these numbers mean that in KIA14, KIA14-G4A and KIA14-G11A about 10 peptide bonds participate in an $\alpha$-helical conformation, while the Ile $\rightarrow$ Ala mutants have only 6-7 helical residues. KIA14-I9A shows the highest helicity amongst these mutants, which suggests that the central region of the peptide is most stable as a helix, while the termini become more readily unfolded when Ile is replaced by Ala- $\mathrm{d}_{3}$.
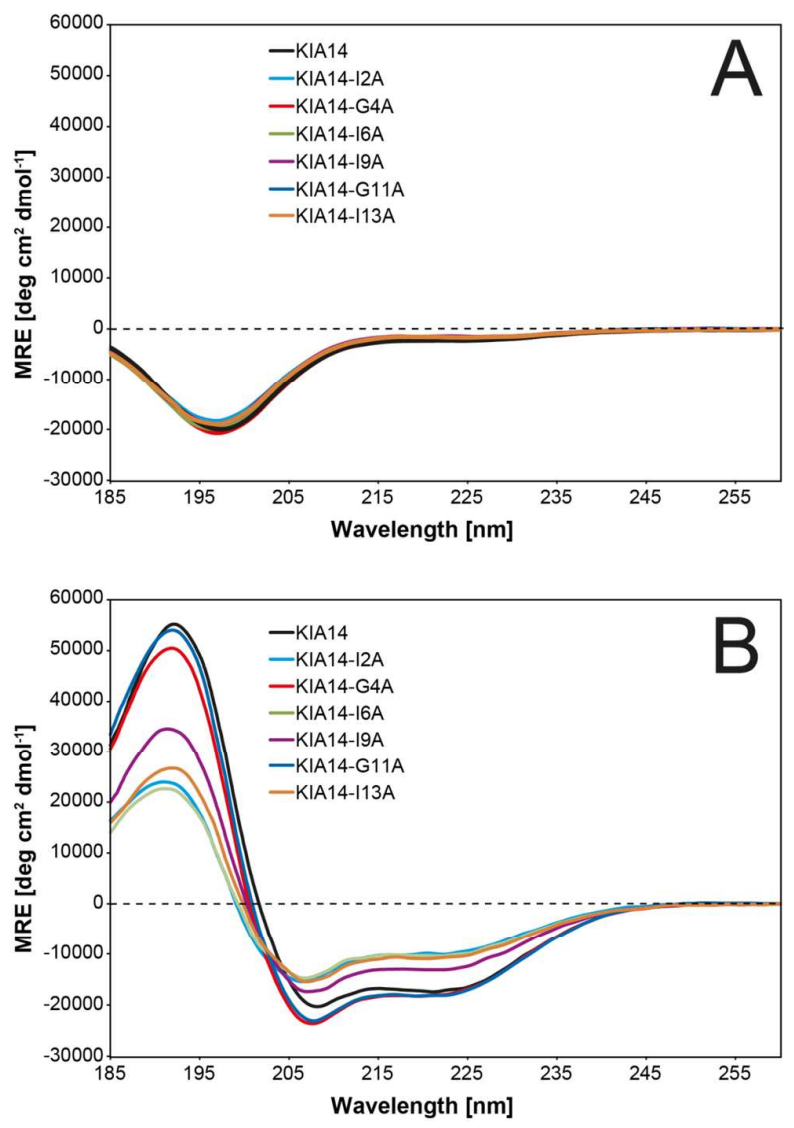

Figure 2. Circular dichroism spectra of KIA14 and the mutants in $10 \mathrm{mM}$ phosphate buffer at $25^{\circ} \mathrm{C}$ (A) and in the presence of DMPC/DMPG (3:1) vesicles at $\mathrm{P} / \mathrm{L}=1: 50$ and $30^{\circ} \mathrm{C}(\mathrm{B})$. 
Table 3. Percentages of secondary structure in KIA14 and its Ala- $\mathrm{d}_{3}$ mutants in the presence of DMPC/DMPG 3/1 vesicles, as evaluated from the CD spectra using three different deconvolution algorithms. ${ }^{\text {a }}$

\begin{tabular}{|l|c|c|c|c|c|}
\hline Peptide & $\begin{array}{c}\text { Total } \\
\text { helix }\end{array}$ & $\begin{array}{c}\text { Total } \\
\text { strand }\end{array}$ & Turns & Unordered & Total \\
\hline KIA14 & $76 \pm 4$ & $4 \pm 2$ & $5 \pm 2$ & $14 \pm 4$ & 99 \\
\hline KIA14-I2A & $43 \pm 4$ & $13 \pm 1$ & $20 \pm 3$ & $25 \pm 3$ & 101 \\
\hline KIA14-G4A & $73 \pm 8$ & $5 \pm 1$ & $8 \pm 3$ & $15 \pm 7$ & 101 \\
\hline KIA14-I6A & $40 \pm 2$ & $13 \pm 2$ & $18 \pm 3$ & $29 \pm 2$ & 100 \\
\hline KIA14-I9A & $52 \pm 3$ & $13 \pm 1$ & $16 \pm 1$ & $19 \pm 3$ & 100 \\
\hline KIA14-G11A & $76 \pm 6$ & $4 \pm 1$ & $6 \pm 2$ & $14 \pm 5$ & 100 \\
\hline KIA14-I13A & $45 \pm 3$ & $12 \pm 3$ & $18 \pm 1$ & $25 \pm 4$ & 100 \\
\hline
\end{tabular}

${ }^{\text {a }}$ Secondary structure estimation from CD spectra was performed using the CDSSTR program with the implemented singular value decomposition (SVD) algorithm, ${ }^{40-41}$ using the CONTIN-LL program that is based on the ridge regression algorithm, ${ }^{42-43}$ and the SELCON-3 program that incorporates the selfconsistent method together with the SVD algorithm to assign protein secondary structure. ${ }^{44-45}$ The three algorithms are provided by the DICHROWEB on-line server. ${ }^{46-47}$ The secondary structure fractions of each sample were calculated as the average value of the individual percentages obtained with the three algorithms. As error estimate is given the standard deviation of the three values from the three algorithms. Individual values were not considered for the average when the sum of all structural elements fractions was $<99 \%$ or $>102 \%$, or when the NMRSD (normalized root mean square deviation) between the experimental and back-calculated $\mathrm{CD}$ spectrum was above the threshold value (0.1 for CONTIN-LL and CDSSTR, and 0.25 for SELCON-3). ${ }^{46}$

\section{Solid-state ${ }^{2}$ H-NMR}

For vesicle experiments with excess water, negatively charged lipids are needed to assure binding of the cationic lipids to the membranes, and therefore PG lipids were included in leakage and CD experiments. In solid-state NMR using oriented samples, hydration is low and peptides are forced to interact also with neutral membranes. ${ }^{28}$ To simplify the systems, only neutral PC lipids were used in the NMR experiments.

In DOPC, all the labelled peptides gave well-resolved ${ }^{2} \mathrm{H}-\mathrm{NMR}$ spectra at the peptide-to-lipid molar ratios (P/L) of 1:50 and 1:20, as seen in Figure 3A and B. A central peak can be observed in all spectra due to residual deuterium in the water used for hydration. Distinct 
quadrupolar splittings with high intensity are always present, originating from peptides that are uniformly aligned in the membrane, thus providing information about peptide orientation. For KIA14-I2A, only a central peak is observed, which might be due to problems with the sample, or simply because the splitting is too small to be resolved and overlaps with the central peak. Because clear splittings are observed for all the other samples, we assume that the splitting is $0 \mathrm{kHz}$ for now. In some spectra, a second doublet with lower intensity is observed which has half of the main splitting, but this is of no concern and can be attributed to mobile peptides in unoriented regions of the sample. ${ }^{17}$ All splittings from oriented peptides at each labelled position are listed in Table 4. The splittings are very similar at the two concentrations, indicating that the peptide orientation remains essentially the same in DOPC. For $\mathrm{P} / \mathrm{L}=1: 50$, orientational analysis using all 10 data points from positions 2 through 14 exhibits a bad fit, with a high RMSD of almost $6 \mathrm{kHz}$. The helical wave plot in Figure 4A shows deviations for several data points, and the minima in the $\tau / \rho$ and $\sigma_{\tau} / \sigma_{\rho}$ plots in Figure 4B and $\mathbf{C}$ are not well defined. The nominal best-fit tilt angle is $\tau=101^{\circ}$, which indicates a flat alignment of the peptide on the membrane surface, in agreement with our earlier ${ }^{15} \mathrm{~N}$ NMR result ${ }^{14}$. The azimuthal angle is $\rho=121^{\circ}$, which is also approximately what is expected, as this corresponds to the charged lysine face pointing towards the water phase. The dynamical parameters are $\sigma_{\tau}=0^{\circ}$ and $\sigma_{\rho}=28^{\circ}$ (Figure 4C), indicating that the tilt angle of the peptide does not fluctuate, while a larger wobble is observed around the helix axis.

The same analysis can now be performed by excluding data from the C-terminal end. When the splitting from position 14 is excluded and data from only positions 2-13 are used, the fit is only marginally better than that when all the points are used (Table S2). Figure 4A shows that the splitting from position 14 fits the curve nicely, indicating that the peptide forms a helix all the way to the C-terminus. Only the splitting from position 13 does not fit so well, but a removal of the data from positions 13 and 14 does not improve the fit very much (Table S3). We also tried to exclude data from both termini by excluding positions 2 and 3, which do not appear to be part of the helix, and one data point from the C-terminus, thus only using data from positions 4 through 13. Because this fit is no better than that including position 14 $($ RMSD $=2.4 \mathrm{kHz})$, we can conclude that the peptide essentially forms an ideal helix from positions 4 through 14. This conclusion is in full agreement with the CD analysis that had shown that about 3 peptide bonds in KIA14 are unfolded. 


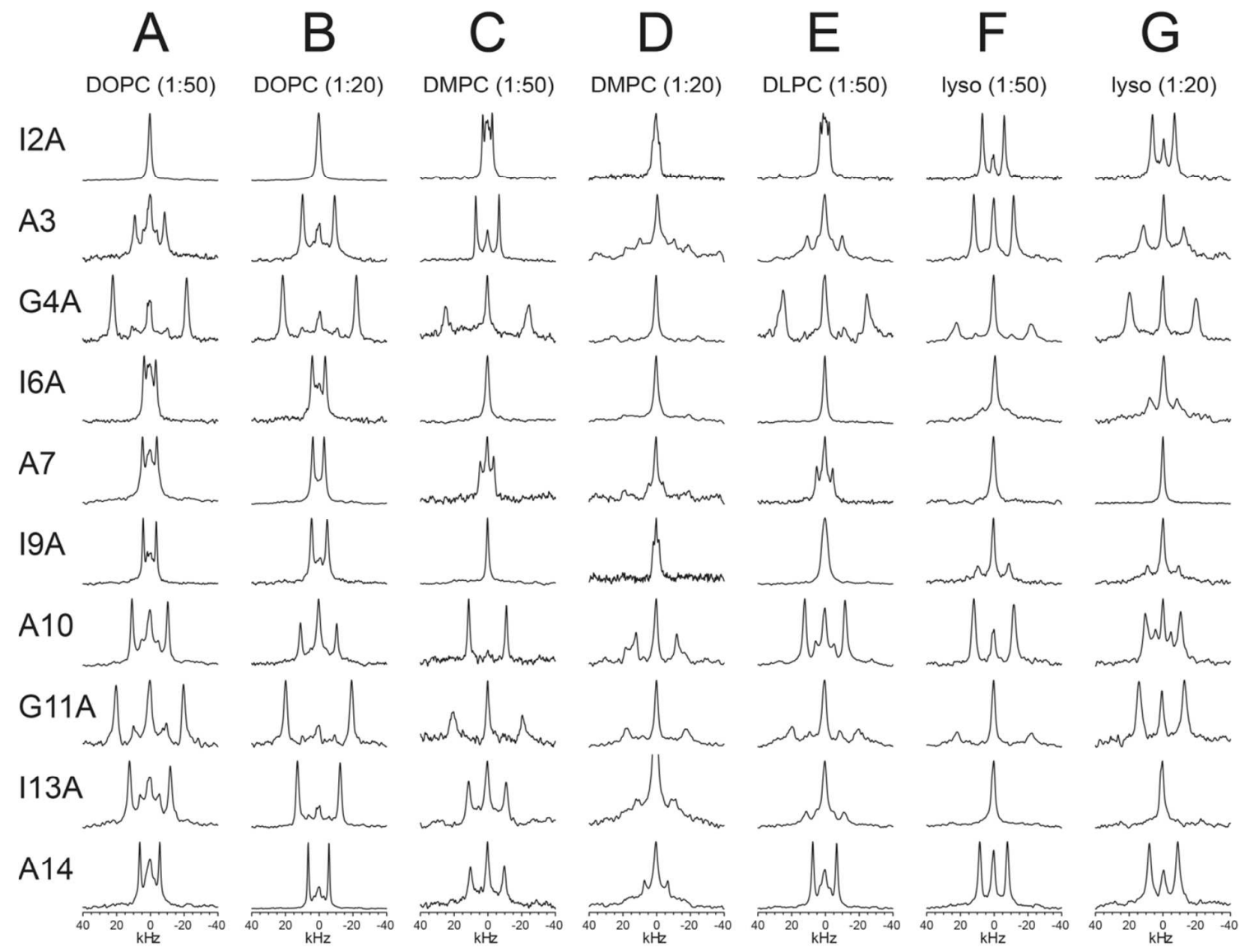

Figure 3. ${ }^{2} \mathrm{H}-\mathrm{NMR}$ spectra of KIA14 labelled at various positions (marked for each row) in different lipid systems (marked for each column) at $35^{\circ} \mathrm{C}$. The $\mathrm{P} / \mathrm{L}$ ratio is shown in brackets in each column. 

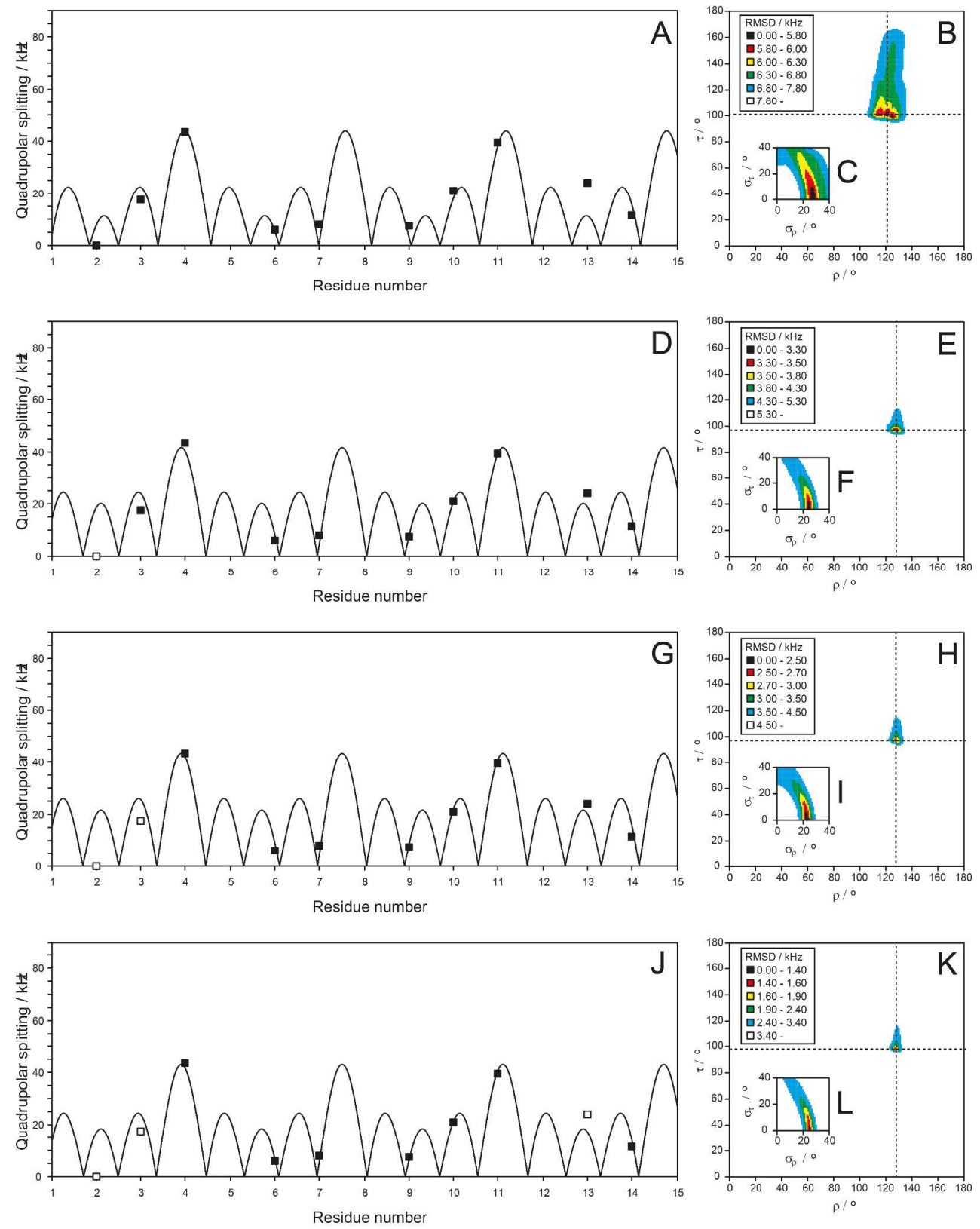

Figure 4. Analysis of the ${ }^{2} \mathrm{H}-\mathrm{NMR}$ data from KIA14 in DOPC at $\mathrm{P} / \mathrm{L}=1: 50$. The left panel in each row shows the best-fit helical wave, in which the quadrupole splittings of the Ala- $\mathrm{d}_{3}$ labelled positions are plotted along the peptide sequence. The right panel in each row shows the RMSD plots of the peptide orientation in terms of $\tau$ and $\rho$, with an inset RMSD plot showing the dynamical parameters $\sigma_{\tau}$ and $\sigma_{\rho}$. (A-C) In the analysis using all 10 labelled positions, the best-fit RMSD is very high. (D-F) When excluding the data point from the label at position I2A (open square), a better RMSD is obtained, with almost the same helix orientation. (G-I) When excluding positions I2A and A3, the RMSD improves further, giving a reliable best-fit orientation of $\tau=97^{\circ}$ and $\rho=128^{\circ}$. (J-L) By excluding positions I2A, A3 and I13A, and even lower RMSD value is obtained, with a best-fit orientation of $\tau=98^{\circ}$ and $\rho=128^{\circ}$. 
Table 4. ${ }^{2} \mathrm{H}-\mathrm{NMR}$ quadrupolar splittings of KIA14 (in kHz).

\begin{tabular}{|l|c|c|c|c|c|c|c|}
\hline & \multicolumn{7}{|c|}{ Lipid system (P/L) } \\
\hline Peptide & $\begin{array}{c}\text { DOPC } \\
(1: 50)\end{array}$ & $\begin{array}{c}\text { DOPC } \\
(1: 20)\end{array}$ & $\begin{array}{c}\text { DMPC } \\
(1: 50)\end{array}$ & $\begin{array}{c}\text { DMPC } \\
(1: 20)\end{array}$ & $\begin{array}{c}\text { DLPC } \\
(1: 50)\end{array}$ & $\begin{array}{c}\text { DMPC/lyso- } \\
\text { MPC 2:1 } \\
(1: 50)\end{array}$ & $\begin{array}{c}\text { DMPC/lyso- } \\
\text { MPC 2:1 } \\
(1: 20)\end{array}$ \\
\hline KIA14-I2A & 0 & 0 & 5.6 & 4.0 & 5.1 & 13.9 & 13.1 \\
\hline KIA14-A3 & 17.7 & 19.0 & 13.8 & 20.2 & 20.7 & 23.6 & 23.9 \\
\hline KIA14-G4A & 43.7 & 43.7 & 48.9 & 49.9 & 49.7 & 44.5 & 39.4 \\
\hline KIA14-I6A & 6.0 & 7.7 & 0 & 0 & 0 & 14.5 & 16.2 \\
\hline KIA14-A7 & 8.4 & 6.7 & 7.9 & 8.3 & 9.4 & 0 & 0 \\
\hline KIA14-I9A & 7.8 & 9.2 & 0 & 3.3 & 0 & 18.5 & 18.5 \\
\hline KIA14-A10 & 21.3 & 21.5 & 22.4 & 24.1 & 23.9 & 23.7 & 21.0 \\
\hline KIA14-G11A & 39.9 & 39.0 & 41.2 & 35.3 & 39.4 & 44.0 & 26.9 \\
\hline KIA14-I13A & 24.1 & 25.3 & 22.2 & 21.3 & 22.3 & 0 & 0 \\
\hline KIA14-A14 & 11.8 & 12.3 & 20.2 & 13.8 & 14.1 & 16.4 & 16.9 \\
\hline
\end{tabular}

The high RMSD is likely due to the peptide being partially unfolded, especially near its termini. This can now be investigated in more detail at a residue-specific level by excluding some data points close to the termini from the fitting procedure. When the splitting from position 2 is excluded from the fit, the quality of the fit improves, giving an RMSD $=3.2 \mathrm{kHz}$ (Figure 4D-F), and the $\tau / \rho / \sigma_{\tau} / \sigma_{\rho}$ minimum becomes better defined. Clearly, the data point from position 2 do not fit the helical wave curve. The resulting helix orientation does not change much compared to that observed using all the data points; the tilt angle is slightly smaller at $97^{\circ}$, the azimuthal angle changes to $128^{\circ}$, and the dynamics are essentially the same. When the data from position 3 is also excluded, the best-fit orientation in terms of $\tau, \rho$, $\sigma_{\tau}$ and $\sigma_{\rho}$ is identical, but the RMSD is further improved to $2.4 \mathrm{kHz}$ (Figure 4G-I, Table S1). This is a reasonably good RMSD value and similar to that previously found for KIA21. ${ }^{24}$ Removing one further data point from position 4 does not improve the fit any more (RMSD = $2.3 \mathrm{kHz}$ ). Thus, it seems that positions 1-3 do not form a helix, but the peptide is helical from position 4 onwards.

We must not forget, however, that some of the data points stem from mutated peptides. As already suggested by the CD deconvolution, some data may not be useful, especially from 
KIA14-I2A and KIA14-I13A, since the helicity of these peptides is considerably lower than that of KIA14. The data from the N-terminal positions I2A and A3 have already been excluded in the ${ }^{2} \mathrm{H}-\mathrm{NMR}$ analysis above, but it may also be risky to include the partially destabilized KIA14-I13A mutant in the structure analysis. The quadrupole splitting of position I13A may well reflect a distorted helix, while KIA14 with an Ala-d $\mathrm{d}_{3}$ label at position A14 would be perfectly unperturbed. Indeed, we observed that the data point from position I13A deviates slightly from the best-fit curve (Figure 4G). If we repeat the analysis after excluding positions I2A, A3 and I13A, a much improved fit with an RMSD of $1.4 \mathrm{kHz}$ is obtained, while the orientation and dynamics of the peptide are essentially the same; the tilt angle here is $98^{\circ}$, and the azimuthal angle is $128^{\circ}$ (Figure 4J-K, Table 5). The corresponding fits for KIA14 in DOPC at a higher peptide concentration of $\mathrm{P} / \mathrm{L}=1: 20$ are shown in Supporting Information Figure S1, and the best-fit parameters are listed in Tables 3 and S1. The results are almost identical to those at $\mathrm{P} / \mathrm{L}=1: 50$.

Table 5. The detailed membrane alignment and dynamical behavior of the amphiphilic helical for KIA14 and KIA21 (MSI-103) peptides was obtained by ${ }^{2} \mathrm{H}-\mathrm{NMR}$ analysis in various lipid systems, giving the best-fit values of the helix tilt angle $\left(\tau /^{\circ}\right)$, azimuthal rotation angle $\left(\rho /{ }^{\circ}\right)$, whole-body fluctuations of $\tau\left(\sigma_{\tau} /{ }^{\circ}\right)$ and $\rho\left(\sigma_{\rho} /{ }^{\circ}\right)$, and the root mean square deviation $(\mathrm{RMSD} / \mathrm{kHz})$.

\begin{tabular}{|l|c|c|c|c|c|c|c|c|c|c|c|c|c|c|c|c|}
\hline & & \multicolumn{4}{|c|}{ KIA14 (all) $^{\mathbf{a}}$} & \multicolumn{4}{|c|}{ KIA14 $^{(\mathbf{2 , 3}, 13)^{\mathbf{b}}}$} & \multicolumn{4}{c|}{ KIA21 (MSI-103) $^{\mathbf{c}}$} \\
\hline Lipid system & $\mathbf{P} / \mathbf{L}$ & $\boldsymbol{\tau}$ & $\boldsymbol{\rho}$ & $\boldsymbol{\sigma}_{\boldsymbol{\tau}}$ & $\boldsymbol{\sigma}_{\boldsymbol{\rho}}$ & $\mathbf{R M S D}$ & $\boldsymbol{\tau}$ & $\boldsymbol{\rho}$ & $\boldsymbol{\sigma}_{\boldsymbol{\tau}}$ & $\boldsymbol{\sigma}_{\boldsymbol{\rho}}$ & $\mathbf{R M S D}$ & $\boldsymbol{\tau}$ & $\boldsymbol{\rho}$ & $\boldsymbol{\sigma}_{\boldsymbol{\tau}}$ & $\boldsymbol{\sigma}_{\boldsymbol{\rho}}$ & $\mathbf{R M S D}$ \\
\hline DOPC & $1: 50$ & 101 & 121 & 0 & 28 & 5.7 & 98 & 128 & 0 & 25 & 1.4 & 94 & 133 & 0 & 14 & 3.2 \\
\hline DOPC & $1: 20$ & 101 & 115 & 6 & 26 & 5.7 & 96 & 128 & 0 & 22 & 2.4 & 93 & 134 & 0 & 13 & 2.8 \\
\hline DMPC & $1: 50$ & 101 & 123 & 0 & 26 & 5.5 & 109 & 124 & 25 & 17 & 2.8 & 127 & 100 & 3 & 2 & 3.4 \\
\hline DMPC & $1: 20$ & 102 & 122 & 7 & 26 & 4.9 & 109 & 123 & 22 & 23 & 3.5 & 126 & 109 & 0 & 0 & 3.8 \\
\hline DLPC & $1: 50$ & 101 & 124 & 0 & 25 & 4.5 & 105 & 125 & 16 & 23 & 2.6 & 123 & 105 & 0 & 18 & 1.4 \\
\hline DMPC/lyso-MPC & $1: 50$ & 146 & 117 & 33 & 13 & 3.3 & 148 & 116 & 31 & 15 & 2.0 & $135^{3}$ & - & - & - & - \\
\hline DMPC/lyso-MPC & $1: 20$ & 163 & 114 & 30 & 2 & 3.6 & 163 & 113 & 28 & 9 & 2.0 & - & - & - & - & - \\
\hline
\end{tabular}

${ }^{\mathrm{a}}$ Using data from all 10 labeled positions in the range of positions 2-14.

${ }^{\mathrm{b}}$ Excluding data from position I2A, A3 and I13A, except for the lyso-MPC systems where only a single data point from position I13A was excluded.

${ }^{c}$ Data from ref. ${ }^{24}$. No ${ }^{2} \mathrm{H}-\mathrm{NMR}$ data is available for KIA21 in DMPC/lyso-MPC systems. But from ${ }^{15} \mathrm{~N}-\mathrm{NMR}$ data the peptide is proposed to be transmembrane in DMPC/lyso-MPC (2:1) and a tilt angle can be estimated at 1:50 from the ${ }^{15} \mathrm{~N}$ chemical shift. ${ }^{14}$ 
The best-fit orientation of KIA14 in DOPC (using data from the folded positions 4-14, except for the partially destabilized Ile13 mutant) and the best-fit orientation of the longer version of the peptide KIA $21^{24}$ are essentially identical (Table 5). The tilt angle $\tau$ of KIA14 is $3^{\circ}$ larger, which is likely within the error of the method. The azimuthal angle $\rho$ is $5-6^{\circ}$ smaller in KIA14, but inspection of their helical wheels shows that the center of the polar sector is shifted $10^{\circ}$ clockwise in KIA14 compared to that in KIA21 (see arrows in Figure 1). Since the observed difference in $\rho$ corresponds to the same direction, the observed decrease of $5-6^{\circ}$ in $\rho$ for KIA14 means that its polar sector is aligned in very much the same way as in KIA21. The shorter peptide appears slightly more dynamic, as the $\sigma_{\rho}$ value is $10^{\circ}$ larger. The result is the same for both KIA21 and KIA14 at P/L = 1:50 and 1:20. A flat orientation of KIA21 on the membrane surface has been observed in a wide range of unsaturated lipid systems, ${ }^{24}$ and is typical for amphipathic peptides in lipid systems with negative spontaneous curvature. ${ }^{25,54}$

In DMPC at $\mathrm{P} / \mathrm{L}=1: 50$, all samples gave clear splittings (Figure 3C), and a fit using all of the data points yields an orientation very similar to that of KIA14 in DOPC. Again, the RMSD in DMPC at $\mathrm{P} / \mathrm{L}=1: 50$ is unacceptably large $(>5 \mathrm{kHz}$ ) (Figure 5A-C). Excluding positions $\mathrm{I} 2 \mathrm{~A}$ and $\mathrm{A} 3$ from the fit results in a better RMSD $(3.8 \mathrm{kHz})$, with a best-fit orientation of $\tau=103^{\circ}$ and $\rho=124^{\circ}$, and best-fit dynamical parameters of $\sigma_{\tau}=18^{\circ}$ and $\sigma_{\rho}=$ $17^{\circ}$ (Table S1). These values indicate larger fluctuations of the tilt angle in DMPC compared to DOPC, while the rotational fluctuations around the helix axis are similar in both lipid systems. After further excluding positions I13A and/or A14 (Tables S2-S4), we found once again that removing position A14 did not improve the fit. Thus, we can conclude that the peptide is also essentially helical for positions 4-14 in DMPC. However, excluding position I13A results in a better fit, with an RMSD of $2.8 \mathrm{kHz}$, corresponding to $\tau=109^{\circ}, \rho=124^{\circ}, \sigma_{\tau}$ $=25^{\circ}$, and $\sigma_{\rho}=17^{\circ}$.

At a high peptide concentration of $\mathrm{P} / \mathrm{L}=1: 20$, the spectra in DMPC do not show as clearly defined peaks as at 1:50 (Figure 3D), though the splittings are similar to those at 1:50 (usually within $2 \mathrm{kHz}$, but in some cases the difference is larger). For labels at positions A3, A7 and A10, a second splitting of $37 \mathrm{kHz}$ is evident, which is typical of aggregated peptides that have become immobilized and unoriented. The same behaviour has also been reported for KIA21 in DMPC/cholesterol. ${ }^{24}$ When the splittings from the oriented peptides are fitted, essentially the same results as for DMPC at 1:50 is obtained (Figure S2 and Table 5). Again, 
fitting of all data points gives a bad fit, but excluding positions I2A, A3 and I13A yields a good fit, with an RMSD of $3.5 \mathrm{kHz}$, corresponding to $\tau=109^{\circ}, \rho=123^{\circ}, \sigma_{\tau}=22^{\circ}$, and $\sigma_{\rho}=$ $23^{\circ}$. The orientation is within $1^{\circ}$ from that found at $1: 50$, which is within the error of the method, and the dynamic parameters are also very similar. As in DOPC, almost no change in the orientation or the dynamics was observed upon increasing the peptide concentration from $1: 50$ to $1: 20$.
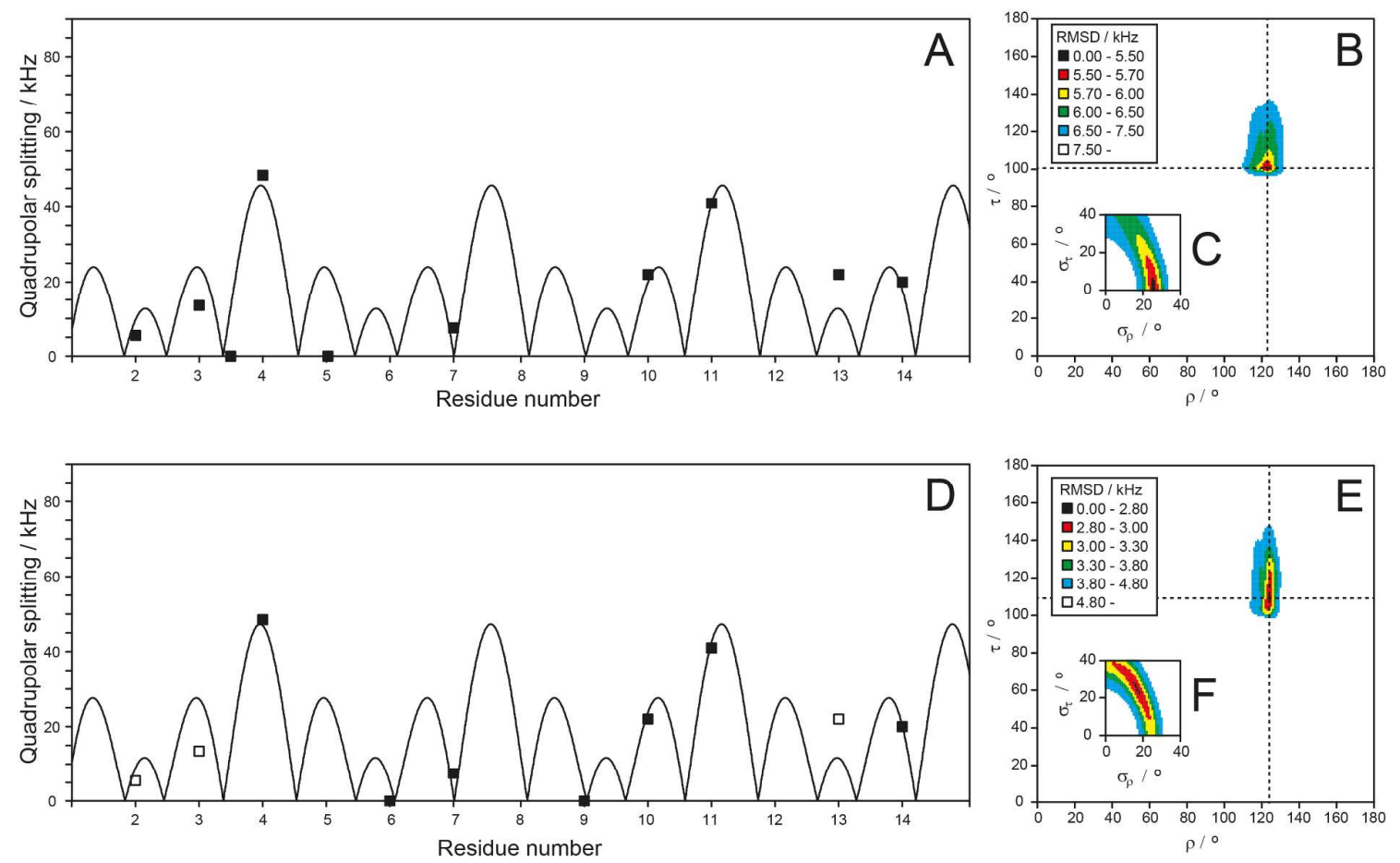

Figure 5. ${ }^{2} \mathrm{H}-\mathrm{NMR}$ data analysis of KIA14 in DMPC at $\mathrm{P} / \mathrm{L}=1: 50$, analogous to Figure 4. (A-C) In the analysis using all 10 labelled positions, the best-fit RMSD is very high. (D-F) When excluding data from labels at positions I2A, A3 and I13A, a low RMSD value is obtained, with a best-fit helix orientation of $\tau=109^{\circ}$ and $\rho=124^{\circ}$.

Also in DLPC at P/L $=1: 50$, there are clean splittings (Figure 3E) that are very similar to those in DMPC at $\mathrm{P} / \mathrm{L}=1: 20$. A fit using all the data points results in an orientation very similar to that of KIA14 in DMPC, with a high RMSD of $4.5 \mathrm{kHz}$. The fits are shown in Figure S3. Again, excluding positions I2A and A3 provided a better fit, and excluding position I13A improved the RMSD to $2.6 \mathrm{kHz}$. The orientation in this case is $\tau=105^{\circ}$ and $\rho=$ $125^{\circ}$, which is very similar to those in DMPC and DLPC. The same correspondence was also previously observed for KIA2 1 in DLPC. ${ }^{24}$

Interestingly, the picture changes when moving to DMPC/lyso-MPC at $\mathrm{P} / \mathrm{L}=1: 50$ and $\mathrm{P} / \mathrm{L}=$ 1:20. All spectra gave clear splittings (Figure 3F and 3G), but they look quite different from 
those observed in the other lipid systems, e.g. at positions I2A and A7 (Figure 3, Table 4), which immediately suggests that the orientation is different. A fit using all ten data points at $\mathrm{P} / \mathrm{L}=1: 50$ gave $\tau=146^{\circ}$ and $\rho=117^{\circ}$. Here, the RMSD is $3.3 \mathrm{kHz}$, which is considerably better than that for the other lipid systems examined above, and as good as those of the other lipid systems after positions I2A and A3 had been excluded. The fit (Figure 6A) shows that only position I13A does not fit the curve. In this case, excluding positions I2A and A3 from the fit only results in a very slight reduction of RMSD to $3.2 \mathrm{kHz}$, which is not a convincing argument to exclude these two N-terminal data points. Removing the C-terminal position A14 also has little effect. Only when position I13A is excluded, the RMSD goes down to $2.0 \mathrm{kHz}$, with $\tau=148^{\circ}$ and $\rho=116^{\circ}$. These findings indicate that the whole peptide from position 2-14 forms an ideal helix in DMPC/lyso-MPC. Only in KIA14-A13A, the splitting does not fit the helical curve, indicating that this mutation perturbs the structure, as already suggested by $\mathrm{CD}$ and as seen in the other lipid systems, too. Interestingly, the helix tilt angle observed here for KIA14 in DMPC/lyso-MPC is $148^{\circ}$, which corresponds to a more upright orientation, where the helix axis is inclined by only about $30^{\circ}$ away from the membrane normal. This structure is in stark contrasts to the helix orientation observed in the other studied lipid systems, in which the peptide is aligned nearly flat on the membrane surface. The upright orientation in DMPC/lyso-MPC also fits with previous ${ }^{15} \mathrm{~N}-\mathrm{NMR}$ data in this lipid mixture ${ }^{14}$. The $\rho$ angle is decreased by about $10^{\circ}$ compared to the value observed for the other systems. The dynamical parameters are $\sigma_{\tau}=31^{\circ}$ and $\sigma_{\rho}=15^{\circ}$, indicating that the fluctuations of the tilt angle are larger in DMPC/lyso-MPC than in pure DMPC, while the fluctuations around the helix axis are similar.

In DMPC/lyso-MPC at a high peptide concentration of $\mathrm{P} / \mathrm{L}=1: 20$, the splittings look quite similar to those at 1:50, with KIA14-G4A and KIA14-G11A being notable exceptions. When all data are analysed together, a rather poor fit is obtained, as the RMSD is $3.6 \mathrm{kHz}$. If positions I2A and A3 are excluded, the fit does not improve. When position I13A is excluded, however, the RMSD is reduced to $2.0 \mathrm{kHz}$, which is a good fit (Figure S4). All calculations yield essentially the same helix orientation of $\tau=163^{\circ}$ and $\rho=113^{\circ}$, whether all data points are included, whether positions I2A and A3 are excluded, or whether position I13A is excluded. The tilt angle describes a very upright helix orientation, as the peptide axis is only inclined by $17^{\circ}$ away from the membrane normal. In this lipid system, we have thus found a clear change in helix orientation with peptide concentration: the tilt angle changes from $148^{\circ}$ at $\mathrm{P} / \mathrm{L}=1: 50$ to $163^{\circ}$ at $\mathrm{P} / \mathrm{L}=1: 20$. This observation is significant, even though the error 
margin in this lipid system is larger, as seen in Figure $\mathbf{6 C}$, making a range of tilt angles compatible with a low RMSD.
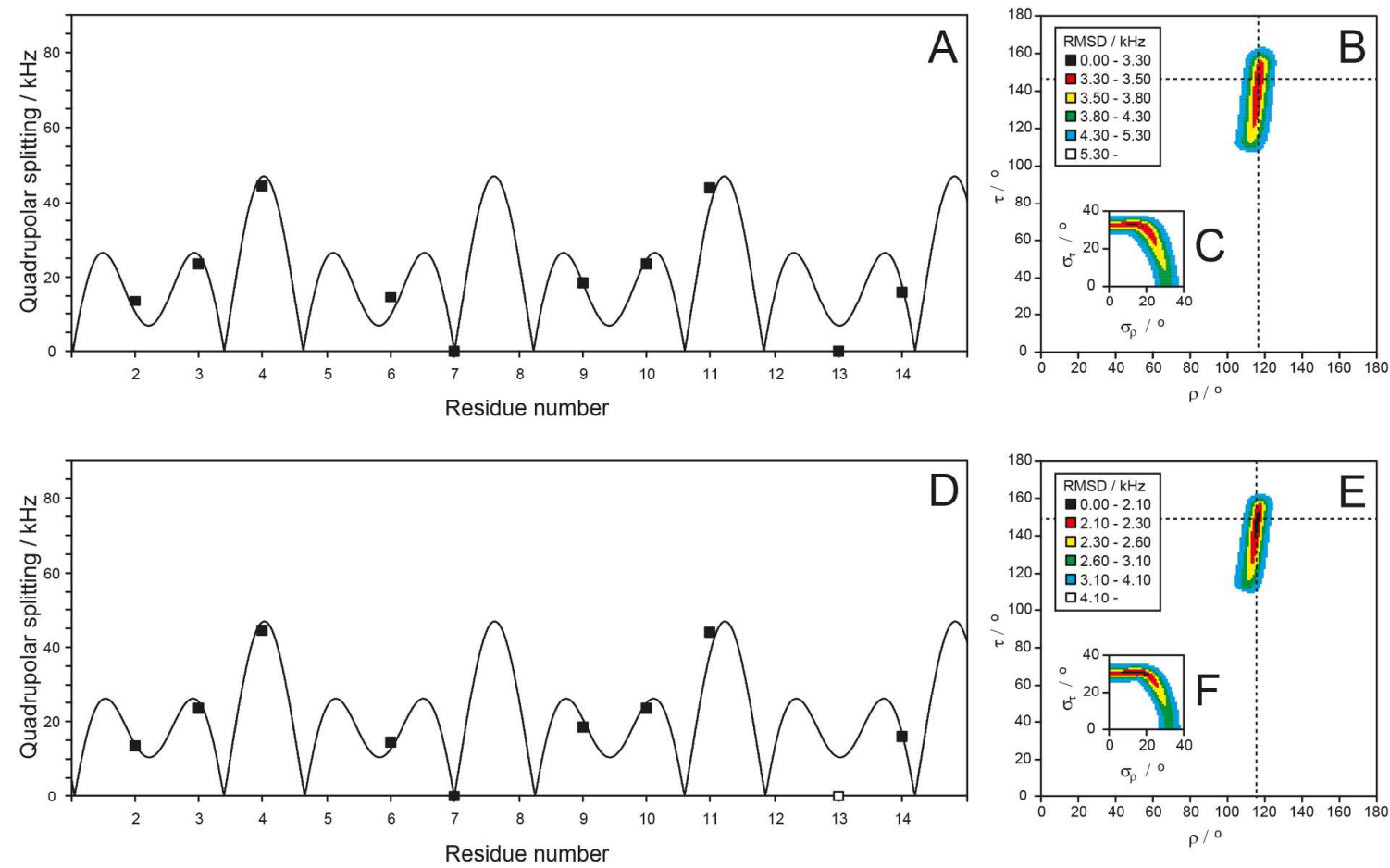

Figure 6. ${ }^{2} \mathrm{H}-\mathrm{NMR}$ data analysis of KIA14 in DMPC/lyso-MPC $(2: 1)$ at $\mathrm{P} / \mathrm{L}=1: 50$, analogous to Figures 4 and 5. (A-C) A fit using all 10 labelled positions gives a resonable RMSD. (D-F) Excluding the data from position I13A gives a good RMSD value, with a best-fit helix orientation of $\tau=148^{\circ}$ and $\rho=116^{\circ}$. 


\section{Discussion}

In this study, we determined the membrane orientation of the amphipathic $\alpha$-helical peptide KIA14 in different lipid bilayers, paying particular attention to helix fraying at the termini. It is highly informative to compare the structural behaviour of this short sequence with previous results obtained for the longer peptide KIA21, which consists of three rather than two repetitive KIAGKIA-motifs.

\section{Helix stability}

To examine the local helicity of an amphipathic $\alpha$-helix bound to a membrane, we used solidstate ${ }^{2} \mathrm{H}-\mathrm{NMR}$ in macroscopically oriented lipid samples, which provides anisotropic local information on specifically labelled segments of a peptide. ${ }^{2} \mathrm{H}$-NMR was chosen rather than ${ }^{15} \mathrm{~N}-\mathrm{NMR}^{55-57}$ or ${ }^{13} \mathrm{C}_{-} \mathrm{NMR}^{58-59}$ - solid-state nuclei which can be used to get similar information - in this study, since we have previously studied the longer KIA21 peptides extensively with ${ }^{2} \mathrm{H}-\mathrm{NMR}^{23-24}$, and also wanted to investigate the effect of Ala mutations on the structure and orientation of the peptides.

In solutions, a more straightforward NMR approach to look at helix fraying has been used, given that the isotropic ${ }^{13} \mathrm{C}$ chemical shift reflects the local secondary structure. Ala-rich model peptides had been specifically labelled with ${ }^{13} \mathrm{C}=\mathrm{O}$ in the backbone, and their helicity was studied as a function of temperature and solvent. ${ }^{60-61}$ In those publications, the central region of these peptides was found to be most persistently helical. A gradual decrease of helicity towards both termini was observed, with variations due to the sequence, which reflects a dynamical opening and closing of hydrogen bonds within the peptide backbone and towards the aqueous solvent. ${ }^{60-61} \mathrm{~A}$ different behaviour may be expected for membrane-bound peptides, because the hydrophobic lipid environment is known to stabilize intramolecular hydrogen bonding. Indeed, the KIA14 peptide is by no means helical but completely disordered in aqueous solution, and it only forms a helix upon binding to a membrane (or micelle or TFE $/ \mathrm{H}_{2} \mathrm{O}$ mixture, data not shown). In the present work, we thus studied the local helicity of a membrane-bound helix to get some original insights into protein folding under these conditions.

In many previous solid-state NMR studies of membrane-bound peptides, only the central stretch of the peptide was labelled, and positions close to the termini were avoided for good reasons. $^{2,5,17-19,23-24,50,62}$ Those precautions made it possible to analyse the anisotropic NMR 
parameters while assuming an ideal $\alpha$-helix or $\beta$-sheet, which was indeed confirmed to be a good approximation for the central region of the peptides in those cases. Obviously, the labels in the middle of the peptide could not provide any information regarding possible fraying of the termini. In some cases Ala residues close to the termini were labeled with Ala- $\mathrm{d}_{3}$ in peptides from the GWALP family. ${ }^{15,30}$ In GWALP23, splittings from position 3 and 21 did not fit the helical curve from the core region, indicating helix unwinding at both termini in the 23-mer peptide. ${ }^{30}$ In $\mathrm{A}^{4,5} \mathrm{GWALP} 23$ and $\mathrm{F}^{4,5} \mathrm{GWALP} 23$, a more thorough study was done of terminal fraying, and it was proposed that the fraying could be a critical stabilizing factor to define the orientation and structure of the transmembrane helix, and also limit its dynamics. ${ }^{15}$ Here, we replaced all residues in the KIA14 sequence with Ala- $\mathrm{d}_{3}$, except for the charged lysines. This virtually complete set of labels yielded data from positions 2-14 along the entire peptide, including positions close to the termini.

When folded as an $\alpha$-helix, KIA14 has an amphipathic structure with bulky hydrophobic Ile residues and positively charged Lys resides protruding on opposite faces, and small Ala and Gly residues in between. The sequence can be written as $\underline{\mathrm{K}} A G \underline{\mathbf{K}} \mathbf{\mathbf { I }} \underline{\mathrm{K}} \mathbf{\mathbf { I }} A G \underline{\mathrm{K}} \mathbf{I} A$ to highlight the charged residues (underlined), the strongly hydrophobic residues (bold) and the small residues (italics). This annotation shows the periodicity of the three classes of amino acid residues (see also Figure 1). If we now replace Ile-13 with Ala, the sequence becomes $\underline{\mathrm{K}} \mathbf{I} A G \underline{\mathrm{K}} \mathbf{I} A \underline{\mathrm{K}} \mathbf{I} A G \underline{\mathrm{K}} A A$, which carries no large hydrophobic residue after Ile-9, hence the five remaining C-terminal residues should be less likely to form an amphipathic helix. This expected behaviour can indeed be observed by CD, where KIA14-I13A shows a much lower helicity than KIA14. In addition, we notice in the helical wave curves that the NMR splitting from KIA14-14A, which has exactly the same sequence as KIA14, fits to the helical curve very well, indicating that this peptide forms an essentially ideal helix all the way to the Cterminus, including Ile-13. However, the splitting from the mutant KIA14-I13A does not fit the helical wave, indicating that the helicity is lower for this peptide, which must have started to unfold at the C-terminus. From these data, we can conclude that the original KIA14 peptide forms an essentially ideal helix all the way up to the C-terminus, whereas the KIA14-I13A mutant is less helical in the $\mathrm{C}$-terminal region.

Likewise, when we replace Ile-2 with Ala-d $\mathrm{d}_{3}$, the sequence changes to $\underline{\mathrm{K}} A A G \underline{\mathrm{K}} \mathbf{I} A \underline{\mathrm{K}} \mathbf{I} A G \underline{\mathrm{K}} \mathbf{I} A$. In this sequence, there is no highly hydrophobic residue in the N-terminal region up to Ile-6, as the first five residues are all charged or small. Thus, the amphipathicity of this segment is 
much lower now, hence this region may potentially not bind to the membrane and/or not form a helix. Indeed, the CD results (Table 3) show that the mutant KIA14-I2A is less helical (43\%) than KIA14 itself (76\%), and the ${ }^{2} \mathrm{H}-\mathrm{NMR}$ splitting from KIA14-I2A does not fit the helical wave curve. The labelled KIA14-A3 has the same sequence as the original peptide, and therefore the same helicity, but its splitting does not fit the helical wave curve. Therefore, we can conclude that this residue Ala-3 is disordered, and that the N-terminus of KIA14 must be frayed out. For the next label in KIA14-G4A, on the other hand, the splitting fits well to the helical wave curve, and so do all other (non-perturbing) labels on the peptide from this position onwards. The CD results show a helicity of 76\%, indicating that out of all 14 amino acids (i.e. 13 peptide bonds), a total of about 10 peptide bonds participate in the helical conformation. Because this CD estimate fits very well with the NMR data, we can conclude that the KIA14 peptide is $\alpha$-helical from position 4 through to 14 (Figure 7).

Our NMR data clearly show that Ile-2 is not part of the helix in the original KIA14 peptide. Obviously, position 2 is also not contained in the helical region of the KIA14-I2A mutant, in which the helicity is reduced to $43 \%$ according to $\mathrm{CD}$, which corresponds to only 5-6 peptide bonds. These observations suggest that the helical segment in KIA14-I2A spans only from Ile-9 through to Ala-14, meaning that the entire N-terminal half of the peptide has lost its helicity and started to unravel when Ile-2 is replaced with Ala. Likewise, in the KIA14-I13A mutant we observed a helicity of only $45 \%$, indicating that only six peptide bonds are in a helical conformation. If we assume that the I13A mutation has little effect on the N-terminus, the helix would begin (as in the original peptide) at position 4 and extend up to Ile-9. Mutating Ile-13 to Ala should thus result in the five C-terminal residues ( $A G \underline{K} A A)$ being nonhelical and frayed out. The tentative helical parts of these peptides are shown in Figure 7. 
KIA14 KIAGKIAKIAGKIA- $\mathrm{NH}_{2}$

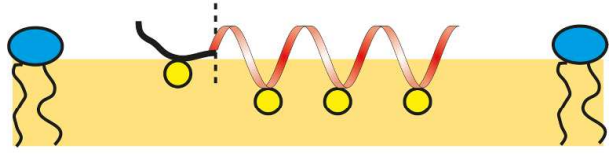

The picture is not as clear-cut for the two central Ile residues, Ile-6 and Ile-9. Both mutants KIA14-I6A and KIA14-I9A are less helical than KIA14 according to CD (42\% and 50\%, respectively), but the ${ }^{2} \mathrm{H}-\mathrm{NMR}$ splittings from the mutants fit perfectly to the helical curve, indicating that these positions are still part of the helix. A plausible explanation for these seemingly contradictory observations would be that these less hydrophobic mutants have a reduced overall binding affinity to the membrane, given that one of their central anchoring Ile residues is missing. As a consequence, a smaller fraction of the peptides would bind to the vesicles in the $\mathrm{CD}$ experiments, which are carried out in a vast excess of aqueous solvent. In this case, the observed average helicity would be reduced, because only those peptide molecules that are bound to the membrane would contribute to the helical CD signal, while the unbound peptides remain disordered in solution. This possibility seems quite likely under CD conditions, even though we had mixed some anionic DMPG lipids into the small unilamellar DMPC vesicles to attract the peptides electrostatically. In contrast, there is no excess bulk water present in the NMR samples, which are prepared just under saturating hydration conditions. In these multilayer samples, all peptides are forced to bind to the membrane, as previously demonstrated. ${ }^{28}$ Altogether, we can conclude from the combination of CD and NMR that Ile-2 is not part of the helix in KIA14, that Ile-13 is necessary for the 
helix to extend all the way to the C-terminus, and that all Ile residues are important for the formation of a membrane-bound helix.

These results fit nicely with those of a previous study, in which two analogues of KIA14 were used that contained two additional Lys residues. ${ }^{36}$ In this $\mathrm{KIA}(7) 14$ mutant [KK $\left.A G \underline{\mathrm{K}} \mathbf{I} A \underline{\mathrm{KK}} A G K \mathbf{I} A-\mathrm{NH}_{2}\right]$, Ile-2 and Ile-8 were replaced by Lys, and this peptide was not helical at all. It only exhibited $3 \%$ helicity in the presence of DMPC/DMPG vesicles according to the deconvoluted CD spectra, indicating that the peptide was not bound to the membrane. In contrast, the mutant KIKA14 [피 $\left.A \underline{\mathrm{KK}} \mathbf{I} A \underline{\mathrm{K}} \mathbf{I} \underline{\mathrm{KK}} \mathbf{I} A-\mathrm{NH}_{2}\right]$, in which Gly-4 and Gly-11 were replaced with Lys but all four Ile residues were retained, showed $80 \%$ helicity, which was similar to that of the original KIA14. ${ }^{36}$ We can thus conclude that for KIA14 the large hydrophobic Ile residues are crucial for its ability to bind to and form an amphipathic $\alpha$ helix in the membrane.

From the vesicle leakage assays, we find a strong correlation between peptide helicity and the ability to induce leakage in DMoPC/DMoPG vesicles (which have short acyl chains). The peptides with Ile $\rightarrow$ Ala- $d_{3}$ mutations, which had a reduced helicity of only $40-52 \%$, gave only a fraction of the leakage found for KIA14, while the Gly $\rightarrow$ Ala- $\mathrm{d}_{3}$ mutants had a higher helicity and stronger leakage. We have previously proposed that peptides of the KIA series must be long enough to span the hydrophobic core of the membrane in order to form pores and induce leakage. ${ }^{13,36}$ Here, we see clearly that when the peptides are not helical, their effective length in the membrane is reduced, as unordered parts are probably not interacting in a stable manner with the membrane. Notably, the KIA(7)14 peptide mentioned above, with almost no helicity, did not induce any leakage in DMoPC/DMoPG vesicles. ${ }^{36}$

In any peptide, the full hydrogen-bonded pattern of an $\alpha$-helix necessarily remains incomplete at both termini, because H-bonds cannot extend beyond the backbone. Interestingly, according to our results, the C-terminus of KIA14 forms a much more stable helix than the Nterminus, even though their amino acid sequences are almost identical. This may be due to the fact that the $\mathrm{C}$-terminal region is more hydrophobic (no charge at the amidated C-terminus) and can therefore bind better to and insert more deeply into the membrane. In addition, we found that in the presence of lyso-lipids, where the entire peptide is inserted more upright in the membrane, the N-terminal region also becomes more helical, as the splittings from positions 2 and 3 now also fit the helical wave curve (Figure 6A). This effect may probably 
be attributed to the assembly of an oligomeric pore, in which a completely folded and wellstructured helical peptide is required to span the hydrophobic membrane core. ${ }^{13-14}$

In a few, very thorough solid-state ${ }^{19}$ F-NMR studies, peptides had also been labelled close to the termini. The cell-penetrating peptide transportan 10 (TP10) was labelled selectively in several places from position 2 to the C-terminal position $21 .^{16}$. In this case, the N-terminal region (residues 1-8) did not form an $\alpha$-helix, and there was no sign of helix fraying at the Cterminus. The short 11 -amino acid multifunctional peptide BP100 ${ }^{63}$ was labelled with ${ }^{19} \mathrm{~F}$ containing amino acids.${ }^{39}$ or Ala-d3, ${ }^{20}$ and no fraying was observed at either terminus.

BP100 does not contain any Gly residues in its sequence, and CD analysis showed BP100 to have a remarkably high $\alpha$-helix content of about $61 \%$. The peptide TP 10 , on the other hand, has two Gly residues in its unstructured N-terminal region, but none in its well folded $\alpha$ helical C-terminal region. Also the peptide of our present interest, KIA14, contains two Gly residues, and replacing them with Ala- $\mathrm{d}_{3}$ increased the helicity. Thus, it appears fully plausible that $\alpha$-helices without Gly (or Pro, a very strong helix breaker) are more rigid and do not fray as much at their termini due to their continuous H-bonding pattern.

\section{Lipid-dependent helix orientation}

For cationic amphipathic peptides, with one charged face and one hydrophobic face, the most straightforward orientation in a lipid membrane is flat on the membrane surface $\left(\tau \approx 90^{\circ}\right)$, with the polar part pointing up to the water phase, and the hydrophobic part pointing into the hydrophobic membrane interior (Figure 8A, left). This is the orientation expected and observed for all peptide studied so far at low $\mathrm{P} / \mathrm{L}$, where the peptides are monomeric. At higher peptide concentration, it has been proposed that peptides can form discrete dimers with an oblique tilt angle $\left(\tau \approx 120^{\circ}\right.$ ) (Figure $8 \mathbf{A}$, middle). At even higher concentrations, under suitable conditions, the peptides can insert further into the membrane as a multimeric pore with a more or less upright, transmembrane orientation $\left(\tau \approx 180^{\circ}\right)$ (Figure 8A, right). The polar residues of the peptides line the aqueous channel, while the hydrophobic ones are anchored in the surrounding lipid bilayer. As there is a dynamical equilibrium between the three states in the membrane, it is important to note that - depending on the conditions - one or the other state will dominate, and the overall time-average amongst them will usually be observed as an angle in the solid-state NMR experiment. 
It is generally known that the membrane orientation of amphipathic helical peptides is strongly influenced by the lipid composition. In particular, we had found that the lipid spontaneous curvature appears to be a key factor. ${ }^{54}$ In lipids with a negative spontaneous curvature, such as DOPC, peptides are always observed to lie flat on the membrane surface, ${ }^{14,20,24-25,54}$ and this was also found for KIA14 in DOPC in the present study, and previously for KIA21 (Figure $\mathbf{8 B}$ ). ${ }^{24}$
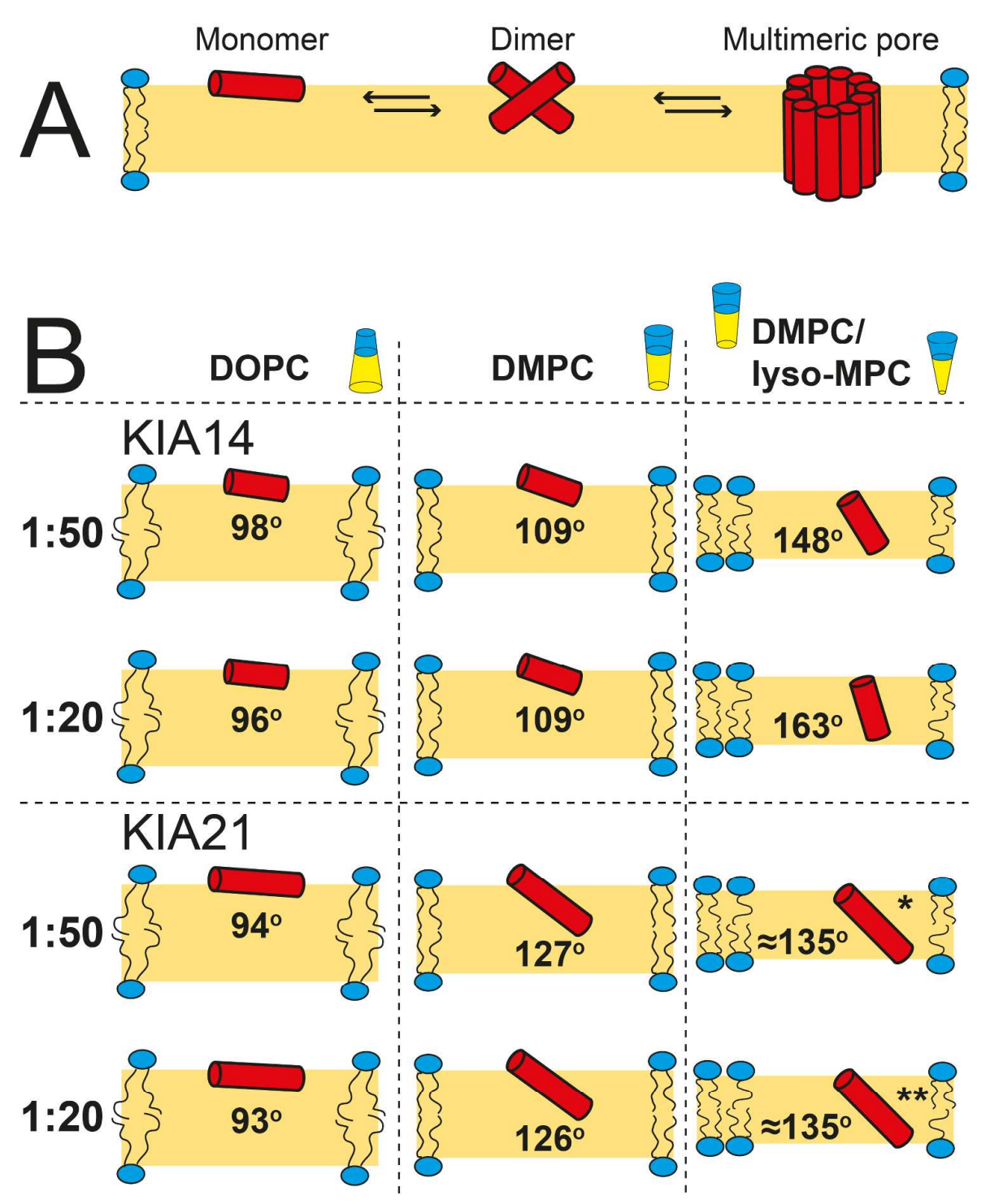

Figure 8. (A) Orientational states of cationic amphipathic helical peptides. Left: As a monomer the peptide is lying almost flat on the membrane surface. Middle: With increasing peptide concentration the tilt angle increases to around $125^{\circ}$, corresponding to a discrete postulated dimer. Right: The peptides can also assemble further into a multimeric pore with the helices in a transmembrane orientation with a more or less upright alignment. (B) Orientation of KIA14 and KIA21 in a membrane, as determined from ${ }^{2} \mathrm{H}-\mathrm{NMR}$. The tilt angle is shown in each case. (For simplicity only 
one peptide is shown in each case, even if peptides are proposed to form dimers or pores.)

* The orientation of KIA21 in DMPC/lyso-MPC at 1:50 is estimated from ${ }^{15} \mathrm{~N}-\mathrm{NMR}$ data; ${ }^{14}$

** at 1:20 the orientation is estimated to be the same as at 1:50, based on the orientation in other lipid systems not changing between 1:50 and 1:20.

In lipids with a low positive spontaneous curvature such as DMPC and DLPC, on the other hand, some peptides stay flat on the surface, while others are able to insert more deeply into the membrane. Now, we can compare the behaviour the short KIA14 with its longer analogue KIA21. In both DMPC and DLPC, the longer peptide exists in a tilted state with a tilt angle of approximately $125^{\circ}$, while KIA14 peptide is only slightly tilted (tilt angle of approximately $105^{\circ}$ ) (Figure 8B). This difference cannot be explained by a change in the mean hydrophobicity of the peptides, by different residues close to the C-terminus (which is inserted deeper into the membrane than the N-terminus), nor by a change in the polar sector size (Figure 1), because these properties are exactly the same for both peptides. Yet, it seems likely that longer peptides would engage in stronger peptide-lipid interactions, and obviously also cover a larger surface area due to their size. Therefore, peptide-peptide interactions in the membrane should also be enhanced in the case of KIA21 compared to KIA14, because the larger peptides are on average closer to each other at the same $\mathrm{P} / \mathrm{L}$ ratio. We found that KIA21 is already strongly tilted at a moderate peptide concentration of 1:50, whereas KIA14 is only slightly tilted at a high concentration 1:20. Therefore, this difference cannot be solely attributed to a crowding effect. We have also noted by NMR that KIA14 is more mobile than KIA21 (Table 5), which is expected for a shorter peptide. This difference is especially large in DMPC, which may indicate that the surface-aligned KIA14 is monomeric, while the tilted KIA21 forms dimers or higher oligomers, aspreviously postulated for the 21-mer PGLa in membranes. ${ }^{19,28,50}$

As mentioned above, in bacterial assays, KIA14 shows no antimicrobial activity, which is likely due to this peptide being too short to span the bacterial membrane and therefore being unable to form a pore. ${ }^{13}$ The length of KIA14 as an ideal helix is $21 \AA$, which is less than the hydrophobic thickness of DMPC of $25.4 \AA$, though similar to the hydrophobic thickness of DLPC of $20.9 \AA .{ }^{64}$ We found that the peptides which are not inserted in these lipid systems do not appear to be fully helical, as only a $76 \%$ helicity was observed according to CD (Table 3 ). Thus, the folded core of KIA14 would probably be shorter than $21 \AA$, and therefore not long enough to span the pure DLPC bilayers. 
In DMPC bilayers containing lyso-PC lipids, which have a highly positive spontaneous curvature, ${ }^{65}$ insertion into a transmembrane state is promoted, and pores are easily formed. Even the short KIA14 peptide can become inserted now, with a very steep tilt angle, which indicates that the lyso-lipids lead to local membrane thinning such that the peptides are able to span the membrane in this case. This ability to insert almost upright had been previously shown by ${ }^{15} \mathrm{~N}-\mathrm{NMR},{ }^{14}$ and was confirmed here with high accuracy using ${ }^{2} \mathrm{H}-\mathrm{NMR}$, which revealed also the corresponding azimuthal rotation $\rho$ and dynamical parameters $\sigma_{\tau}$ and $\sigma_{\rho}$. Because KIA14 carries several charged residues on one face, it is unlikely to span the membrane as a monomer, so the highly tilted state must correspond to an oligomeric transmembrane pore, as previously discussed. ${ }^{14}$ In our earlier ${ }^{15} \mathrm{~N}-\mathrm{NMR}$ study, KIA21 was also found to be inserted in DMPC/lyso-MPC in a transmembrane orientation, as was the whole series of KIA-type peptides that were 14 to 28 amino acids in length. Their helix tilt angle was seen to change gradually, with KIA14 being the most upright, and with increasing helix length the peptides tilted more and more away from the membrane normal. This way, they could adapt their individual effective hydrophobic length to the membrane thickness in a mismatch-dependent manner. ${ }^{14}$ The concept of hydrophobic matching had been observed and discussed so far only for completely hydrophobic segments of peptides and integral proteins, ${ }^{66}$ but clearly holds also for amphiphilic peptides.

Finally, we can now compare the different types of model lipid systems in terms of their suitability to detect re-alignment events of membrane-active peptides, which are often found to be concentration-dependent and indicative of oligomerization and/or pore formation (Table 3). In DOPC and DMPC, the orientation of KIA14 (in the form of flat monomers, and obliquely tilted dimers, respectively) did not change upon increasing the peptide concentration from $\mathrm{P} / \mathrm{L}=1: 50$ to $1: 20$. On the other hand, in DMPC/lyso-MPC the short KIA14 helix was steeply inserted (and hardly frayed out), and it showed a concentrationdependent change in tilt angle of $15^{\circ}$. Similarly, in a previous study of the longer KIA21 peptide (called MSI), no concentration dependence was observed in DOPC or DMPC between $\mathrm{P} / \mathrm{L}=1: 50$ and $1: 20 .^{24}$

To summarize these observations on lipid dependence: in extreme cases, in which the lipids have a highly positive or negative spontaneous curvature, the helix orientation and oligomeric state appears to be determined mostly by the lipids. We therefore propose that lipids with a 
spontaneous curvature close to zero, like DMPC and DLPC, are more suitable lipid systems in which the more subtle effects of peptide modifications should be compared, e.g. how mutations, charge, hydrophobicity, or peptide length influence the ability of amphipathic peptides to be inserted into membranes. Under these conditions, it might be possible to screen for the most strongly membranolytic antimicrobial and/or cytotoxic peptides.

\section{Conclusions}

$\mathrm{CD}$ and solid-state NMR are used here as complementary methods to study the global and local helicity of the membrane-bound amphipathic peptide KIA14. The methods agree well and give information about the fraying at the peptide termini. KIA14 forms an essentially ideal helix from residue 4 to 14 . When Gly residues are mutated to Ala, the helicity increases. On the other hand, when Ile residues are mutated to Ala, the helicity is dramatically reduced. This indicates that the hydrophobic Ile side chain is needed to anchor the peptide to the membrane and when they are removed the peptide is partially unbound and loses locally its helical structure. This loss of helicity also leads to a loss of activity, as seen by a reduced ability to induce leakage of vesicles. The orientation of KIA14 is the same as that of the longer KIA21 peptide in DOPC bilayers, where both peptides are lying flat on the membrane surface. In DMPC/lyso-MPC lipids, both peptides are inserted into a membrane-spanning orientation, with a tilt angle which depends on hydrophobic matching. In DMPC and DLPC, there is a difference between the orientation of the two peptides, and the shorter KIA14 is more flat on the surface, whereas the longer KIA21 is found in a tilted state. This difference is likely due to stronger peptide-peptide interactions between the longer peptides.

\section{Supporting information}

The Supporting Information is available ...

Tables describing results of fits of ${ }^{2} \mathrm{H}-\mathrm{NMR}$ data using different sets of data points (Tables S1-S4). Best-fit analysis in DOPC at P/L=1:20 (Fig. S1), in DMPC at 1:20 (Fig. S2), in DLPC at $\mathrm{P} / \mathrm{L}=1: 50$ (Fig. S3) and in DMPC/lyso-MPC at $\mathrm{P} / \mathrm{L}=1: 20$ (Fig. S4).

\section{Acknowledgements}

We thank Andrea Eisele and Kerstin Scheubeck for their help with peptide synthesis and purification, David Benz and Dr. Johannes Reichert for help with leakage measurements, and Dr. Stephan Grage and Markus Schmitt for their help with the NMR infrastructure. We acknowledge financial support from the Helmholtz Association program BioInterfaces in 


\section{References}

1. Brogden, K. A. Antimicrobial peptides: pore formers or metabolic inhibitors in bacteria? Nat. Rev. Microbiol. 2005, 3, 238-250.

2. Strandberg, E.; Tremouilhac, P.; Wadhwani, P.; Ulrich, A. S. Synergistic transmembrane insertion of the heterodimeric PGLa/magainin 2 complex studied by solid-state NMR. Biochim. Biophys. Acta 2009, 1788, 1667-1679.

3. Sani, M. A.; Separovic, F. How membrane-active peptides get into lipid membranes. Acc. Chem. Res. 2016, 49, 1130-1138.

4. Langel, Ü., Cell-Penetrating Peptides: Processes and Applications. CRC Press: Boca Raton, FL, 2002; p 406.

5. Wadhwani, P.; Bürck, J.; Strandberg, E.; Mink, C.; Afonin, S.; Ulrich, A. S. Using a sterically restrictive amino acid as a ${ }^{19} \mathrm{~F}-\mathrm{NMR}$ label to monitor and control peptide aggregation in membranes. J. Am. Chem. Soc. 2008, 130, 16515-16517.

6. Reichert, J.; Grasnick, D.; Afonin, S.; Bürck, J.; Wadhwani, P.; Ulrich, A. S. A critical evaluation of the conformational requirements of fusogenic peptides in membranes. Eur. Biophys. J. 2007, 36, 405-413.

7. Grasnick, D.; Sternberg, U.; Strandberg, E.; Wadhwani, P.; Ulrich, A. S. Irregular structure of the HIV fusion peptide in membranes demonstrated by solid-state NMR and MD simulations. Eur. Biophys. J. 2011, 40, 529-543.

8. Tamm, L. K.; Han, X.; Li, Y.; Lai, A. L. Structure and function of membrane fusion peptides. Biopolymers 2002, 66, 249-60.

9. Boman, H. G. Antibacterial peptides: basic facts and emerging concepts. J. Int. Med. 2003, 254, 197-215.

10. Wang, G.; Li, X.; Wang, Z. APD2: the updated antimicrobial peptide database and its application in peptide design. Nucleic Acids Res. 2009, 37, D933-7.

11. Zasloff, M. Magainins, a class of antimicrobial peptides from Xenopus skin: isolation, characterization of two active forms, and partial cDNA sequence of a precursor. Proc. Natl. Acad. Sci. U.S.A. 1987, 84, 5449-5453.

12. Agerberth, B.; Gunne, H.; Odeberg, J.; Kogner, P.; Boman, H. G.; Gudmundsson, G. H. FALL-39, a putative human peptide antibiotic, is cysteine-free and expressed in bone marrow and testis. Proc. Natl. Acad. Sci. U.S.A. 1995, 92, 195-199.

13. Grau-Campistany, A.; Strandberg, E.; Wadhwani, P.; Reichert, J.; Bürck, J.; Rabanal, F.; Ulrich, A. S. Hydrophobic mismatch demonstrated for membranolytic peptides, and their use as molecular rulers to measure bilayer thickness in native cells. Sci. Rep. 2015, 5, 9388.

14. Grau-Campistany, A.; Strandberg, E.; Wadhwani, P.; Rabanal, F.; Ulrich, A. S. Extending the hydrophobic mismatch concept to amphiphilic membranolytic peptides. $J$. Phys. Chem. Lett. 2016, 7, 1116-1120. 
15. Mortazavi, A.; Rajagopalan, V.; Sparks, K. A.; Greathouse, D. V.; Koeppe, R. E., II. Juxta-terminal helix unwinding as a stabilizing factor to modulate the dynamics of transmembrane helices. ChemBioChem 2016, 17, 462-5.

16. Fanghänel, S.; Wadhwani, P.; Strandberg, E.; Verdurmen, W. P. R.; Bürck, J.; Ehni, S.; Mykhailiuk, P. K.; Afonin, S.; Gerthsen, D.; Komarov, I. V., et al. Structure analysis and conformational transitions of the cell penetrating peptide transportan 10 in the membrane-bound state. PLoS One 2014, 9, e99653.

17. Strandberg, E.; Özdirekcan, S.; Rijkers, D. T. S.; Van der Wel, P. C. A.; Koeppe, R. E., II; Liskamp, R. M. J.; Killian, J. A. Tilt angles of transmembrane model peptides in oriented and non-oriented lipid bilayers as determined by ${ }^{2} \mathrm{H}$ solid state NMR. Biophys. J. 2004, 86, 3709-3721.

18. Van der Wel, P. C. A.; Strandberg, E.; Killian, J. A.; Koeppe, R. E., II. Geometry and intrinsic tilt of a tryptophan-anchored transmembrane $\alpha$-helix determined by ${ }^{2} \mathrm{H}$ NMR. Biophys. J. 2002, 83, 1479-1488.

19. Strandberg, E.; Wadhwani, P.; Tremouilhac, P.; Dürr, U. H. N.; Ulrich, A. S. Solid-state NMR analysis of the PGLa peptide orientation in DMPC bilayers: structural fidelity of ${ }^{2} \mathrm{H}$-labels versus high sensitivity of ${ }^{19} \mathrm{~F}-\mathrm{NMR}$. Biophys. J. 2006, 90, 1676-1686.

20. Zamora-Carreras, H.; Strandberg, E.; Mühlhäuser, P.; Bürck, J.; Wadhwani, P.; Jiménez, M. Á.; Bruix, M.; Ulrich, A. S. Alanine scan and ${ }^{2} \mathrm{H}$ NMR analysis of the membraneactive peptide BP100 point to a distinct carpet mechanism of action. Biochim. Biophys. Acta 2016, 1858 1328-1338.

21. Strandberg, E.; Tiltak, D.; Ieronimo, M.; Kanithasen, N.; Wadhwani, P.; Ulrich, A. S. Influence of C-terminal amidation on the antimicrobial and hemolytic activities of cationic $\alpha$-helical peptides. Pure Appl. Chem. 2007, 79, 717-728.

22. Maloy, W. L.; Kari, U. P. Structure-activity studies on magainins and other host-defense peptides. Biopolymers 1995, 37, 105-122.

23. Strandberg, E.; Kanithasen, N.; Bürck, J.; Wadhwani, P.; Tiltak, D.; Zwernemann, O.; Ulrich, A. S. Solid state NMR analysis comparing the designer-made antibiotic MSI-103 with its parent peptide PGLa in lipid bilayers. Biochemistry 2008, 47, 2601-2616.

24. Strandberg, E.; Tiltak, D.; Ehni, S.; Wadhwani, P.; Ulrich, A. S. Lipid shape is a key factor for membrane interactions of amphipathic helical peptides. Biochim. Biophys. Acta 2012, 1818, 1764-1776.

25. Strandberg, E.; Zerweck, J.; Wadhwani, P.; Ulrich, A. S. Synergistic insertion of antimicrobial magainin-family peptides in membranes depends on the lipid spontaneous curvature. Biophys. J. 2013, 104, L9-11.

26. Strandberg, E.; Horn, D.; Reißer, S.; Zerweck, J.; Wadhwani, P.; Ulrich, A. S. ${ }^{2}$ H-NMR and MD simulations reveal membrane-bound conformation of magainin 2 and its synergy with PGLa. Biophys. J. 2016, 111, 2149-2161.

27. Strandberg, E.; Esteban-Martín, S.; Salgado, J.; Ulrich, A. S. Orientation and dynamics of peptides in membranes calculated from ${ }^{2} \mathrm{H}-\mathrm{NMR}$ data. Biophys. J. 2009, 96, 32233232 .

28. Tremouilhac, P.; Strandberg, E.; Wadhwani, P.; Ulrich, A. S. Conditions affecting the realignment of the antimicrobial peptide PGLa in membranes as monitored by solid state ${ }^{2}$ H-NMR. Biochim. Biophys. Acta 2006, 1758, 1330-1342.

29. Gleason, N. J.; Vostrikov, V. V.; Greathouse, D. V.; Koeppe, R. E., II. Buried lysine, but not arginine, titrates and alters transmembrane helix tilt. Proc. Natl. Acad. Sci. U.S.A. 2013, 110, 1692-5.

30. Vostrikov, V. V.; Daily, A. E.; Greathouse, D. V.; Koeppe, R. E., II. Charged or aromatic anchor residue dependence of transmembrane peptide tilt. J. Biol. Chem. 2010, 285, 31723-30. 
31. Daily, A. E.; Greathouse, D. V.; van der Wel, P. C. A.; Koeppe, R. E., II. Helical distortion in tryptophan- and lysine-anchored membrane-spanning $\alpha$-helices as a function of hydrophobic mismatch: a solid-state deuterium NMR investigation using the geometric analysis of labeled alanines method. Biophys. J. 2008, 94, 480-491.

32. Carpino, L. A.; Han, G. Y. 9-Fluorenylmethoxycarbonyl amino-protecting group. J. Org. Chem. 1972, 37, 3404-3409.

33. Fields, G. B.; Noble, R. L. Solid-phase peptide synthesis utilizing 9fluorenylmethoxycarbonyl amino acids. Int. J. Pept. Protein Res. 1990, 35, 161-214.

34. Duzgunes, N.; Wilschut, J. Fusion assays monitoring intermixing of aqueous contents. Methods Enzymol. 1993, 220, 3-14.

35. Steinbrecher, T.; Prock, S.; Reichert, J.; Wadhwani, P.; Zimpfer, B.; Bürck, J.; Berditsch, M.; Elstner, M.; Ulrich, A. S. Peptide-lipid interactions of the stress-response peptide TisB that induces bacterial persistence. Biophys. J. 2012, 103, 1460-1469.

36. Gagnon, M. C.; Strandberg, E.; Grau-Campistany, A.; Wadhwani, P.; Reichert, J.; Burck, J.; Rabanal, F.; Auger, M.; Paquin, J. F.; Ulrich, A. S. Influence of the length and charge on the activity of $\alpha$-helical amphipathic antimicrobial peptides. Biochemistry 2017, 56, 1680-1695.

37. Mayer, L. D.; Hope, M. J.; Cullis, P. R. Vesicles of variable sizes produced by a rapid extrusion procedure. Biochim. Biophys. Acta 1986, 858, 161-168.

38. Ellens, H.; Bentz, J.; Szoka, F. C. $\mathrm{H}^{+}-$and $\mathrm{Ca}^{2+}$-induced fusion and destabilization of liposomes. Biochemistry 1985, 24, 3099-3106.

39. Wadhwani, P.; Strandberg, E.; van den Berg, J.; Mink, C.; Bürck, J.; Ciriello, R.; Ulrich, A. S. Dynamical structure of the short multifunctional peptide BP100 in membranes. Biochim. Biophys. Acta 2014, 1838, 940-949.

40. Johnson, W. C. Analyzing protein circular dichroism spectra for accurate secondary structures. Proteins 1999, 35, 307-12.

41. Sreerama, N.; Venyaminov, S. Y.; Woody, R. W. Estimation of protein secondary structure from circular dichroism spectra: inclusion of denatured proteins with native proteins in the analysis. Anal. Biochem. 2000, 287, 243-51.

42. Provencher, S. W.; Glockner, J. Estimation of globular protein secondary structure from circular dichroism. Biochemistry 1981, 20, 33-7.

43. van Stokkum, I. H.; Spoelder, H. J.; Bloemendal, M.; van Grondelle, R.; Groen, F. C. Estimation of protein secondary structure and error analysis from circular dichroism spectra. Anal. Biochem. 1990, 191, 110-8.

44. Sreerama, N.; Venyaminov, S. Y.; Woody, R. W. Estimation of the number of $\alpha$-helical and $\beta$-strand segments in proteins using circular dichroism spectroscopy. Protein Sci. 1999, 8, 370-80.

45. Sreerama, N.; Woody, R. W. A self-consistent method for the analysis of protein secondary structure from circular dichroism. Anal. Biochem. 1993, 209, 32-44.

46. Whitmore, L.; Wallace, B. A. DICHROWEB, an online server for protein secondary structure analyses from circular dichroism spectroscopic data. Nucleic Acids Res. 2004, 32, W668-73.

47. Lobley, A.; Whitmore, L.; Wallace, B. A. DICHROWEB: an interactive website for the analysis of protein secondary structure from circular dichroism spectra. Bioinformatics 2002, 18, 211-2.

48. Rance, M.; Byrd, R. A. Obtaining high-fidelity spin-1/2 powder spectra in anisotropic media - phase-cycled Hahn echo spectroscopy. J. Magn. Reson. 1983, 52, 221-240.

49. Davis, J. H.; Jeffrey, K. R.; Bloom, M.; Valic, M. I.; Higgs, T. P. Quadrupolar echo deuteron magnetic resonance spectroscopy in ordered hydrocarbon chains. Chem. Phys. Lett. 1976, 42, 390-394. 
50. Glaser, R. W.; Sachse, C.; Dürr, U. H. N.; Afonin, S.; Wadhwani, P.; Strandberg, E.; Ulrich, A. S. Concentration-dependent realignment of the antimicrobial peptide PGLa in lipid membranes observed by solid-state ${ }^{19}$ F-NMR. Biophys. J. 2005, 88, 3392-3397.

51. Davis, J. H. The description of membrane lipid conformation, order and dynamics by ${ }^{2} \mathrm{H}-$ NMR. Biochim. Biophys. Acta 1983, 737, 117-171.

52. Glaser, R. W.; Sachse, C.; Dürr, U. H. N.; Wadhwani, P.; Ulrich, A. S. Orientation of the antimicrobial peptide PGLa in lipid membranes determined from ${ }^{19} \mathrm{~F}-\mathrm{NMR}$ dipolar couplings of 4-CF 3 -phenylglycine labels. J. Magn. Reson. 2004, 168, 153-163.

53. Strandberg, E.; Ulrich, A. S., Dynamic structure analysis of peptides in membranes by solid-state NMR. In Advances in Biological Solid-State NMR: Proteins and MembraneActive Peptides, Separovic, F.; Naito, A., Eds. Royal Society of Chemistry: London, 2014; pp 304-319.

54. Strandberg, E.; Ulrich, A. S. AMPs and OMPs: Is the folding and bilayer insertion of $\beta$ stranded outer membrane proteins governed by the same biophysical principles as for $\alpha$ helical antimicrobial peptides? Biochim. Biophys. Acta 2015, 1848, 1944-54.

55. Bechinger, B.; Gierasch, L. M.; Montal, M.; Zasloff, M.; Opella, S. J. Orientations of helical peptides in membrane bilayers by solid state NMR spectroscopy. Solid State Nucl. Magn. Reson. 1996, 7, 185-191.

56. Wang, J.; Denny, J.; Tian, C.; Kim, S.; Mo, Y.; Kovacs, F.; Song, Z.; Nishimura, K.; Gan, Z.; Fu, R., et al. Imaging membrane protein helical wheels. J. Magn. Reson. 2000, 144, 162-167.

57. Marassi, F. M.; Opella, S. J. A solid-state NMR index of helical membrane protein structure and topology. J. Magn. Reson. 2000, 144, 150-155.

58. Smith, R.; Separovic, F.; Milne, T. J.; Whittaker, A.; Bennett, F. M.; Cornell, B. A.; Makriyannis, A. Structure and orientation of the pore-forming peptide, melittin, in lipid bilayers. J. Mol. Biol. 1994, 241, 456-466.

59. Naito, A. Structure elucidation of membrane-associated peptides and proteins in oriented bilayers by solid-state NMR spectroscopy. Solid State Nucl. Magn. Reson. 2009, 36, 6776.

60. Song, K.; Stewart, J. M.; Fesinmeyer, R. M.; Andersen, N. H.; Simmerling, C. Structural insights for designed alanine-rich helices: Comparing NMR helicity measures and conformational ensembles from molecular dynamics simulation. Biopolymers 2008, 89, 747-760.

61. Fesinmeyer, R. M.; Peterson, E. S.; Dyer, R. B.; Andersen, N. H. Studies of helix fraying and solvation using 13C' isotopomers. Protein Sci. 2005, 14, 2324-32.

62. Wadhwani, P.; Strandberg, E.; Heidenreich, N.; Bürck, J.; Fanghänel, S.; Ulrich, A. S. Self-assembly of flexible $\beta$-strands into immobile amyloid-like $\beta$-sheets in membranes as revealed by solid-state ${ }^{19}$ F NMR. J. Am. Chem. Soc. 2012, 134, 6512-6515.

63. Badosa, E.; Ferre, R.; Planas, M.; Feliu, L.; Besalu, E.; Cabrefiga, J.; Bardaji, E.; Montesinos, E. A library of linear undecapeptides with bactericidal activity against phytopathogenic bacteria. Peptides 2007, 28, 2276-85.

64. Kucerka, N.; Liu, Y.; Chu, N.; Petrache, H. I.; Tristram-Nagle, S.; Nagle, J. F. Structure of fully hydrated fluid phase DMPC and DLPC lipid bilayers using X-ray scattering from oriented multilamellar arrays and from unilamellar vesicles. Biophys. J. 2005, 88, 262637.

65. Fuller, N.; Rand, R. P. The influence of lysolipids on the spontaneous curvature and bending elasticity of phospholipid membranes. Biophys. J. 2001, 81, 243-54.

66. Strandberg, E.; Esteban-Martín, S.; Ulrich, A. S.; Salgado, J. Hydrophobic mismatch of mobile transmembrane helices: merging theory and experiments. Biochim. Biophys. Acta 2012, 1818, 1242-1249. 


\section{Table of Contents (TOC) Image}

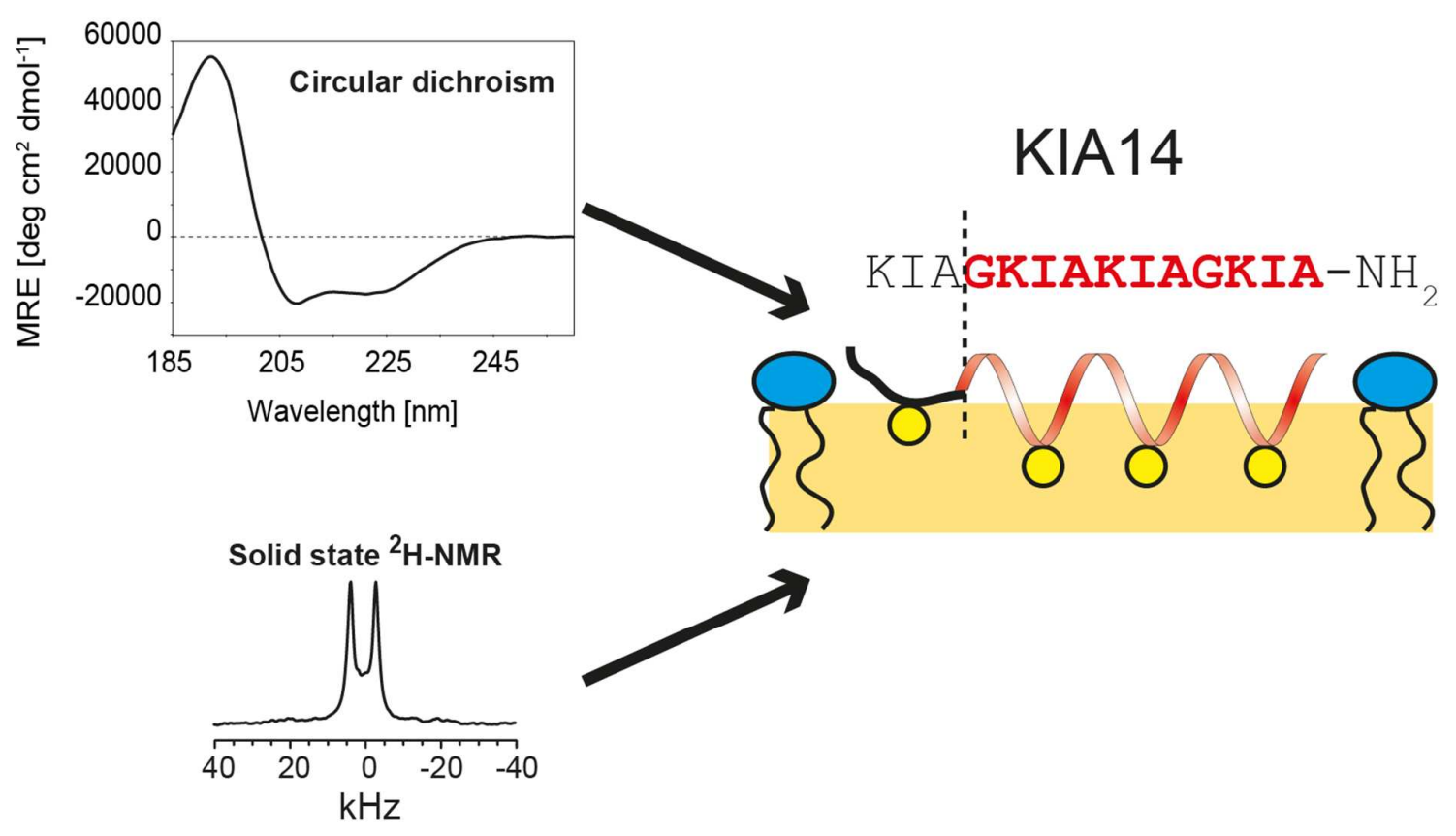

